Nat. Hazards Earth Syst. Sci., 20, 1867-1887, 2020

https://doi.org/10.5194/nhess-20-1867-2020

(C) Author(s) 2020. This work is distributed under

the Creative Commons Attribution 4.0 License.

\title{
Ambient conditions prevailing during hail events in central Europe
}

\author{
Michael Kunz $^{1,2}$, Jan Wandel ${ }^{1}$, Elody Fluck ${ }^{1, a}$, Sven Baumstark ${ }^{1, b}$, Susanna Mohr ${ }^{1,2}$, and Sebastian Schemm ${ }^{3}$ \\ ${ }^{1}$ Institute of Meteorology and Climate Research (IMK), Karlsruhe Institute of Technology (KIT), Karlsruhe, Germany \\ ${ }^{2}$ Center for Disaster Management and Risk Reduction Technology, Karlsruhe Institute of Technology (KIT), \\ Karlsruhe, Germany \\ ${ }^{3}$ Institute for Atmospheric and Climate Science, ETH Zürich, Zurich, Switzerland \\ ${ }^{a}$ now at: Department of Earth and Planetary Sciences, Weizmann Institute of Science, Rehovot, Israel \\ ${ }^{b}$ now at: Heine + Jud, Stuttgart, Germany
}

Correspondence: Michael Kunz (michael.kunz@kit.edu)

Received: 13 December 2019 - Discussion started: 2 January 2020

Revised: 5 May 2020 - Accepted: 2 June 2020 - Published: 1 July 2020

\begin{abstract}
Around 26000 severe convective storm tracks between 2005 and 2014 have been estimated from 2D radar reflectivity for parts of Europe, including Germany, France, Belgium, and Luxembourg. This event set was further combined with eyewitness reports, environmental conditions, and synoptic-scale fronts based on the ERA-Interim (ECMWF Reanalysis) reanalysis. Our analyses reveal that on average about a quarter of all severe thunderstorms in the investigation area were associated with a front. Over complex terrains, such as in southern Germany, the proportion of frontal convective storms is around $10 \%-15 \%$, while over flat terrain half of the events require a front to trigger convection.

Frontal storm tracks associated with hail on average produce larger hailstones and have a longer track. These events usually develop in a high-shear environment. Using composites of environmental conditions centered around the hailstorm tracks, we found that dynamical proxies such as deeplayer shear or storm-relative helicity become important when separating hail diameters and, in particular, their lengths; 0$3 \mathrm{~km}$ helicity as a dynamical proxy performs better compared to wind shear for the separation. In contrast, thermodynamical proxies such as the lifted index or lapse rate show only small differences between the different intensity classes.
\end{abstract}

\section{Introduction}

Severe convective storms (SCSs) are responsible for almost one-third of the total damage by natural hazards in Germany and central Europe (MunichRe, 2020). Examples of recent major loss events include the two supercells on 2728 July 2013 related to the depression Andreas with economic losses of EUR 3.6 billion mainly due to large hail (Kunz et al., 2018) or storm clusters during Ela on 810 July 2014 with economic losses of EUR 2.6 billion (SwissRe, 2015) caused by both large hail and severe wind gusts (Mathias et al., 2017). Given the major damage associated with SCSs, particularly due to large hail, there is a considerable and increasing need to better understand the local probability of SCSs, their intensity, and their relation to prevailing atmospheric precursors.

Several authors have attempted to establish relations between SCSs and hailstorms and favorable atmospheric environments (for Europe: Manzato, 2005; Groenemeijer and van Delden, 2007; Kunz, 2007; Sánchez et al., 2009, 2017; Mohr and Kunz, 2013; Púčik et al., 2015; Madonna et al., 2018, among others). Hail-conductive environments have been estimated either from proximity soundings or from model or reanalysis data, both available over several decades and, depending on the spatial resolution, on a regional, continental, or global scale. According to Púčik et al. (2015), for example, large hail with a diameter of at least $2 \mathrm{~cm}$ most likely forms in environments with high values of increasing convective available energy (CAPE) and bulk wind shear. While the former is directly related to the intensity of the updraft, the latter is decisive for the organization's form of the convective systems - single cells, multicells, supercells, and mesoscale convective systems (MCSs; Markowski and Richardson, 2010). In addition, several studies have suggested that SCSs preferentially occur during specific weather 
regimes, such as European or Scandinavian blocking or teleconnection patterns (Aran et al., 2011; García-Ortega et al., 2011; Kapsch et al., 2012; Piper et al., 2019; Mohr et al., 2019). However, to date, no study has investigated environmental conditions according to hailstone size and hail swath (envelope encompassing all hail streaks; footprint), despite their relevance to overall storm damage.

Forecast experience has shown that synoptic fronts, particularly cold fronts during the summer months, can significantly modify the convective environment, primarily due to increasing convective available energy (CAPE) and decreasing convective inhibition (CIN) in combination with crossfrontal circulations leading to lifting and enhanced vertical wind shear. By combining hailstorm tracks determined from radar data over Switzerland between 2002 and 2013 with front detections (Schemm et al., 2015) based on the Consortium for Small-Scale Modeling (COSMO) analysis, Schemm et al. (2016) found that up to $45 \%$ of storms in northeastern and southern Switzerland were associated with a cold front. They concluded that mainly wind-sheared environments created by the fronts provide favorable conditions for hailstorms in the absence of topographic forcing.

Difficulties in analyzing environmental conditions prior to or during hailstorms usually arise from insufficient direct hail observations that may serve as the ground truth. The number of ground weather stations is too small to reliably detect all SCSs. High-density hailpad networks exist in only a few regions across Europe (e.g., Merino et al., 2014; Hermida et al., 2015) and therefore cannot be used to reproduce entire hailstorm footprints. In order to compensate for this monitoring gap, remote sensing instruments, such as satellites (Bedka, 2011; Punge et al., 2017; Ni et al., 2017; Mroz et al., 2017), lightning (Chronis et al., 2015; Wapler, 2017), or radars (Holleman et al., 2000; Puskeiler et al., 2016; Nisi et al., 2018), due to their area-wide observability, are used to estimate the frequency and intensity of SCSs. In particular, weather radars can give some indications of hail occurrence using either radar reflectivity above a certain threshold (e.g., Mason, 1971; Hohl et al., 2002) or at specific elevations in combination with different height specifications (melting level, $-20^{\circ} \mathrm{C}$ environmental temperature, and top of the storm cell; Waldvogel et al., 1979; Smart and Alberty, 1985; Witt et al., 1998). While observations by dual-polarization radars offer better predictions for hail (e.g., Heinselman and Ryzhkov, 2006; Ryzhkov et al., 2013; Ryzhkov and Zrnic, 2019) these systems have been installed in Europe only recently and cannot be used for climatological studies.

Another important data source for hail is severe-weather reports from trained storm spotters or eyewitnesses that are pooled into severe-weather archives such as the European Severe Weather Database (ESWD; Dotzek et al., 2009). Although reporting is selective and biased towards population density and available spotters, these reports provide valuable information about the intensity of the various convective phenomena associated with SCSs such as maximum hail diame- ter. The combination of these reports with storm tracks estimated from radar observations allows us to reconstruct entire footprints of SCSs and/or hailstorms.

In our study, we have reconstructed SCS tracks from 2D radar reflectivity using a cell-tracking algorithm during a 10-year period (2005-2014) over central Europe including France, Germany, Belgium, and Luxembourg. As our focus in on SCSs, we considered only tracks above a reflectivity of $Z \geq 55 \mathrm{dBZ}$, a threshold frequently used as hail criterion (e.g., Holleman et al., 2000; Hohl et al., 2002; Kunz and Kugel, 2015; Puskeiler et al., 2016). In order to include additional information on the maximum hail diameter of the SCSs, a subsample of hailstorms (HSs) was created by combining the radar-derived SCS tracks with ESWD hail reports.

Afterward, we investigate characteristics and environmental conditions at the time and location of the events unfolding for different classes of hail diameter, track lengths (lifetime), and the relationship with synoptic-scale fronts. Environmental conditions are assessed by constructing composites of meteorological fields from the ERA-Interim (ECMWF Reanalysis) reanalysis centered around the location of a single storm. To estimate the effects of subgrid-scale spatial variations on environmental conditions, for example, by disturbances induced by orographic features or by temperature and moisture advection, we additionally used the coastDat-3 (set of consistent ocean and atmospheric data) reanalysis with a resolution about 6 times higher compared to ERA-Interim.

The main scientific questions of our study are the following:

- How frequent are SCSs associated with a front?

- Do the characteristics of SCSs associated with a synoptic cold front differ from those without a front?

- How do the environmental conditions in terms of thermodynamical and dynamical parameters differ between hail diameter classes, track lengths, and frontal and nonfrontal events?

- How does a higher model resolution affect the environmental conditions around the SCSs?

The paper is structured as follows: Sect. 2 introduces the datasets and methods used. Section 3 deals with the frequency of SCSs and HSs, and Sect. 4 examines the role of synoptic cold fronts and convective storms. Section 5 statistically investigates environmental conditions prevailing around the storms for different classes of hail size and track length. Section 6 synthesizes and summarizes the major findings, while the most important conclusions are drawn in Sect. 7. 


\section{Data and methods}

The investigation area is central Europe, including Germany, France, Belgium, and Luxembourg, from 2005 to 2014, where data were available. Since SCSs and HSs in Europe occur mainly in the summer half-year (SHY; Berthet et al., 2011; Punge and Kunz, 2016; Púčik et al., 2019), all analyses refer to the period from April to September.

\subsection{ESWD hail reports}

The ESWD, managed and maintained by the European Severe Storms Laboratory (ESSL), is the only multinational database and by far the largest archive of hail reports in Europe. Quality-checked reports of SCSs and related phenomena originate from storm chasers and trained spotters, sometimes supplemented by newspaper reports. In our study, we consider the reported maximum hail diameters of all quality levels $(70.4 \%$ of all reports were confirmed; $29.0 \%$ were at least plausibility checked). This includes both large hail with a diameter of at least $2 \mathrm{~cm}$ usually given in increments of $1 \mathrm{~cm}$ (in rare cases of $0.5 \mathrm{~cm}$ ) and hail layers with a depth of at least $10 \mathrm{~cm}$, regardless of hail diameter. In those cases, and when a hail size is not specified (usually in the case of small hail), the diameter is set to $1 \mathrm{~cm}$.

During the 10-year investigation period, a total of 4577 reports of severe hail in the study area are available. Most reports stem from Germany (76.5\%), followed by France (21.1\%), Belgium (1.7\%), and Luxembourg (0.7\%). This distribution does not reflect the occurrence probability of SCSs but is primarily due to the ESSL originally being a German initiative.

Because of the large spatial extent of the study area in a west-east direction, we converted the timestamps for the daily cycle analysis (only for that; cf. Fig. 2) from UTC into local time (LT) by adding $\Delta t=24 \mathrm{~h} / 360^{\circ}$ lat $=4$ min per degree starting from $0^{\circ}$ lat.

\subsection{Reanalyses}

Atmospheric conditions prevailing over a larger area around the SCS tracks are studied using the ERA-Interim (Dee et al., 2011) reanalysis from the European Center for MediumRange Forecast (ECMWF). This dataset, which was also used for the detection of synoptic cold fronts (see Sect. 2.3), is represented as spherical harmonics at a T255 spectral resolution (approx. $80 \mathrm{~km}$ ) on 60 vertical levels from the surface up to $0.1 \mathrm{hPa}$ with a temporal resolution of $6 \mathrm{~h}$. In order to estimate the effects of the model resolution on the dynamic and thermodynamic environmental conditions, we additionally used high-resolution coastDat-3 reanalysis data for selected variables. This second reanalysis from the HelmholtzZentrum Geestacht (HZG) has a spatial and temporal resolution of $0.11^{\circ}$ (approx. $10 \mathrm{~km}$ ) and $1 \mathrm{~h}$, respectively. It was produced by dynamically downscaling ERA-Interim using COSMO in climate mode (CCLM; Rockel et al., 2008).

Mesoscale environments of the hailstorm tracks are characterized by severe-storm predictors representing both thermodynamical and dynamical conditions. We tested and applied several convection-related parameters but focus here only on those proxies with the highest prediction skill: surface lifted index (SLI) representing latent instability (Galway, 1956), lapse rate (LR) as the temperature difference between 700 and $500 \mathrm{hPa}$ representing potential instability (only for coastDat-3), deep-layer shear (DLS) as the difference of the wind vectors between $500 \mathrm{hPa}$ and the surface, and $0-3 \mathrm{~km}$ storm-relative helicity (SRH) quantified by

$$
\begin{aligned}
\mathrm{SRH} & =\int\left(\boldsymbol{v}_{\mathrm{h}}-\boldsymbol{c}\right) \cdot\left(\boldsymbol{\nabla} \times \boldsymbol{v}_{\mathrm{h}}\right) \mathrm{d} z, \\
& =\int\left[-\left(u-c_{x}\right)\left(\frac{\partial v}{\partial z}\right)+\left(v-c_{y}\right)\left(\frac{\partial u}{\partial z}\right)\right] \mathrm{d} z,
\end{aligned}
$$

where $\boldsymbol{v}_{h}=(u, v)$ is the horizontal wind vector and $\boldsymbol{c}=\left(c_{x}\right.$, $c_{y}$ ) is the (constant) cell motion vector, which is usually estimated from a semi-empirical relation such as that from Bunkers et al. (2000). As the convective cell-tracking algorithm directly computes $\boldsymbol{c}$ for each SCS or HS event (see next Sect. 2.4), we used these values to quantify SRH in addition to the vertical wind shear provided by ERA-Interim. Helicity is a measure of the degree to which the direction of motion is aligned with the (horizontal) vorticity of the environment $\omega_{\mathrm{h}}=\boldsymbol{\nabla} \times \boldsymbol{v}_{\mathrm{h}}$ (Markowski and Richardson, 2010). Only streamwise vorticity, which is a prerequisite for supercells bearing the largest hailstones, contributes to SRH (Thompson et al., 2007).

\subsection{Cold-front detection}

Synoptic-scale cold fronts are detected in ERA-Interim based on the method outlined in Schemm et al. (2015), which is briefly summarized here. To identify and locate fronts in the reanalysis, we used the thermal front parameter (TFP; Renard and Clarke, 1965; Hewson, 1998) defined as

$\mathrm{TFP}=-\nabla\left|\nabla \theta_{\mathrm{e}}\right| \cdot \frac{\nabla \theta_{\mathrm{e}}}{\left|\nabla \theta_{\mathrm{e}}\right|}$,

where $\theta_{\mathrm{e}}$ denotes the equivalent potential temperature at $850 \mathrm{hPa}$, a widely used choice in the forecasting community, which also neglects sea-breeze fronts. The first term in Eq. (3) represents the gradient of the frontal zone $\left(\left|\nabla \theta_{\mathrm{e}}\right|\right)$, which must be higher than $4 \mathrm{~K}(100 \mathrm{~km})^{-1}$. The second term is the unit vector of the $\theta_{\mathrm{e}}$ gradient. The TFP hence captures changes of the gradient of the frontal zone along the gradient itself. The frontal zone is strongest where TFP $=0$, and its leading edge is where TFP $=\max$. For the detection of propagating synoptic fronts, which are in the focus here because of their relevance for convection triggering, we require all fronts to have a length of at least $500 \mathrm{~km}$ and a minimum advection 
speed of $3 \mathrm{~m} \mathrm{~s}^{-1}$. These two thresholds may seem somewhat artificial or arbitrary. But as shown by Schemm et al. (2015), their implementation sufficiently removes the land-sea contrast and thermal boundaries from Alpine pumping from the dataset and limit the data to fronts typically associated with extratropical cyclones.

\subsection{Radar data and storm tracking}

Tracks of SCSs are identified from 2D radar reflectivity based on the precipitation scan at low elevation angles. Radar data with a spatial and temporal resolution of $1 \mathrm{~km}$ and $5 \mathrm{~min}$, respectively, were provided by Météo France and by the German Weather Service (DWD) as entire radar composites. Whereas all 17 German radars operate in the $\mathrm{C}$ band, 19 radars in France are in the $\mathrm{C}$ band, and 5 each are in the $\mathrm{S}$ band and $\mathrm{X}$ band. The area in France covered by the $\mathrm{S}$-band radars is rather small ( $<5 \%$ of the total area) compared to that captured by the $\mathrm{C}$ band, and these are mainly restricted to the southwest (S-band radars at Opoul, Nîmes, Bollène, and Collobrières). Because of the dominance of $\mathrm{C}$ band radars, we did not distinguish between the two radar types. X-band radars, exclusively operating in the Maritime Alps in southeastern France, are not considered due to their strong attenuation of the radar signal.

Storm tracks were reconstructed by applying a modified version of the cell-tracking algorithm TRACE3D originally designed for 3D reflectivity in spherical coordinates (Handwerker, 2002). Thus, TRACE3D has to be modified to rely on 2D radar reflectivity in Cartesian coordinates (Fluck, 2017). The tracking algorithm first identifies all convective cells (reflectivity core; RC) embedded into larger "regions of intense precipitation" (ROIP; Handwerker, 2002). Afterward, the weighted center (barycenter) of all RCs is tracked spatially over subsequent time intervals $\mathrm{d} t$ by establishing a temporal connection between the detected RCs. For each RC, a 2D shift velocity vector $\boldsymbol{v}_{T}$ is calculated in different ways, depending on whether and over what distance an RC has already been detected in previous scans. The new position of the RC is estimated from $\boldsymbol{s}_{T}=\boldsymbol{v}_{T} \cdot \delta t$ within a certain search radius $r$, which depends on the length of $s_{T}$ and the distance to the closest neighboring $\mathrm{RC}$. This process is repeated for all subsequent scans until the complete track of a convective cell is reconstructed. The algorithm considers different processes such as cell splitting or merging. Correction algorithms are implemented for undesired radar effects such as the bright band or anomalous propagation (so-called anaprop). In addition, we eliminated all single grid points with high radar reflectivity but without lightning within a radius of $10 \mathrm{~km}$. This filter is based on the assumption that SCSs are always accompanied by lightning. Note that the filter only eliminates single spurious signals but keeps the tracks that are composed of numerous radar grid points.

In our analyses, we considered only storm tracks above a threshold of $Z \geq 55 \mathrm{dBZ}$, referred to as the Mason (1971) criterion for hail detection. Several studies have provided evidence that this lower threshold is suitable to identify hail in radar data (e.g., Holleman et al., 2000; Hohl et al., 2002; Kunz and Kugel, 2015; Puskeiler et al., 2016). However, high radar reflectivity does not guarantee that there is hail on the ground, mainly because of potential melting hailstones and the relation $Z \sim D^{6}$, where $D$ is the hail size diameter. For example, the evaluation of radar-derived cell tracks with damage data from two insurance companies by Puskeiler et al. (2016) has shown that the Mason (1971) criterion provides a satisfactory probability of detection (62\% and $55 \%$ ) but also a high false-alarm rate $(35 \%$ and $40 \%)$. This means that our SCS sample based on this criterion consists mainly of hailstorms but also includes some heavy-rain events (see Sect. 2.5.2 for the definition of the HS sample).

Each SCS event, defined as an entire track reconstructed by the tracking algorithm, contains the following parameters: center (latitude and longitude) of the track including date and time, mean angle, width, total length, and duration; the latter two quantities allow us to compute the storm motion vectors $c$ required for SRH (cf. Eq. 1). For further details on the tracking and the results, see the study by Fluck (2017).

\subsection{Combination of SCS tracks with other parameters}

\subsubsection{Combination of SCSs with fronts}

To match the SCS tracks with synoptic front detections (cf. Sect. 2.3), we first compute the minimum horizontal distance $d_{i}$ between the two events:

$d_{i}=\sqrt{\left(a_{i} \cdot \cos (\mathrm{lat} \cdot 2 \pi / 360) \cdot l\right)^{2}+\left(b_{i} \cdot l\right)^{2}}$,

where $a_{i}$ is the longitudinal distance between a frontal grid point $i$ and the grid points of an individual storm track, $b_{i}$ is the same for the latitude, "lat" is the position (latitude) of the storm track, and $l$ is the (constant) distance of $1^{\circ}$ latitude $(\approx 111.32 \mathrm{~km})$. The cos function in the equation takes into account the poleward convergence of the lines of longitude. For each front detection, we compute the distance $d_{i}$ to all grid points defining the track of an SCS identified in the same $6 \mathrm{~h}$ period. The minimum of all $d_{i}$ values, thus $d_{\min }=\min \left(d_{i}\right)$, defines the minimum distance between the front and the related SCS.

Frontal SCSs are defined as those events where a front is located within a search radius of $R=L / 2+200 \mathrm{~km}$ ( $L$ is the length of an SCS track) around the storm track, i.e., when $d_{i}<R$. Assuming a front acts as a potential trigger for convection, the distance between the two events must be limited (Trapp, 2013). For this reason and because of the low temporal and spatial resolution of the front detections, we set the constant part of $R$ to $200 \mathrm{~km}$. Note that changing this part to a value of 300 or $400 \mathrm{~km}$ has no significant effect on the results. The constant part in $R(L / 2)$ considers only the time of the center of the SCSs for the synchronization between the two events. The longer $L$ value is, the larger the temporal and 
spatial difference between tracks and fronts can be and, thus, the larger $R$ must be.

To account for temporal coincidence, we consider the timestamp of the SCS centers that must be within the period of the front detections (00:00, 06:00, 12:00, and 18:00 UTC). When the SCS center is exactly between the ERA-Interim run times (03:00, 09:00, 15:00, and 21:00 UTC), both time frames are used in the calculations of $d_{i}$. Since the front detections are available for $6 \mathrm{~h}$ intervals only, the time difference between the centers of the SCS and the fronts is at most $3 \mathrm{~h}$. Considering the start time of the SCS instead of that at the center has only a small marginal effect on the results because of both the low temporal resolution of the reanalysis and the comparatively short duration of the SCS tracks (exponential distribution; $73 \%$ of all SCSs have a duration of $2 \mathrm{~h}$ and less).

\subsubsection{Combination of SCS tracks with ESWD data}

The SCS tracks derived from the radar composites are additionally combined with the ESWD reports to assign each track a maximum hail diameter. This step not only ensures that the resulting subsample hailstorms (HSs) consists of hail events solely but also merges hailstorm tracks and maximum hail diameters. This is done by considering both the date and time and the horizontal distance $d_{i}$ between a certain track and the nearest ESWD report in the same way as described above for the fronts. Only ESWD reports with $d_{\min } \leq 10 \mathrm{~km}$ to the closest grid point are considered; these storms are hereafter referred to as hailstorm (HS) events or tracks. A tolerance of $10 \mathrm{~km}$ is necessary for two reasons: in some cases, the ESWD reports do not give an exact position, and hailstones falling to the ground may drift with the horizontal wind over distances of several kilometers (Schuster et al., 2006). When an ESWD report coincides with several tracks, we further considered the time of the report if specified. Cases which are still unclear (around 100 events corresponding to $2 \%$ of all cases) were not considered in the event set. If more than one ESWD report is assigned to a single storm track, we considered only that with the maximum reported hail diameter.

For all investigations, we separated the maximum hailstone diameter into three different classes (samples): $D<$ $3 \mathrm{~cm}$ (48.0\% of all HS tracks), $3 \leq D \leq 4.5 \mathrm{~cm}(37.0 \%)$, and $D \geq 5 \mathrm{~cm}(15.0 \%)$.

\subsubsection{Composite construction}

The investigation of the environmental conditions around the HS tracks is based on composites of convection-related parameters from ERA-Interim. The composites are obtained by averaging the environmental fields of moving spatial windows of $800 \mathrm{~km}$ in latitude and longitude around the center of individual HS tracks (i.e., $\pm 400 \mathrm{~km}$ to the north, south, east, and west from the center of the track). The center of the composites represents the location of all HS tracks. Similar com- posites have already been used by Graf et al. (2011) to investigate central European tornado environments. The effect of latitudinal dependence on the horizontal difference between the grid points in the reanalysis is considered by transferring the latter to Cartesian coordinates with a grid resolution of approximately $50 \mathrm{~km}$. As mentioned above, using the start location instead of the center does not affect the results because of the limited spatial extent of the tracks (mean lengths of frontal and non-frontal HS tracks are 56.8 and $96.2 \mathrm{~km}$, respectively). In addition, due to the low resolution of the ERAInterim data, it can be assumed that the convective environment is not modified by ongoing convective storms. Temporal coincidence is ensured by using the reanalysis fields with the smallest time difference to the HS events. Therefore, the largest time difference between the environmental conditions and the HS events is $3 \mathrm{~h}$.

The single ERA-Interim fields are averaged either for all events or for different categories of events related to hail diameter classes, HS track lengths, and frontal vs. non-frontal HS events. Since most of the HS events propagate from the southwest to the northeast ( $67.6 \%$ between 180 and $270^{\circ}$ ), we have not aligned the fields accordingly. Note, however, that according to a test where this was realized, the results remained essentially the same.

\section{Frequency of SCSs and HSs}

During the investigation period, 26012 SCS tracks were identified. The combination of those tracks with ESWD reports substantially reduced the sample size to 985 HS tracks. The main reason for the much lower number of HS compared to SCS events is an underreporting of hail events, especially over France (Groenemeijer et al., 2017), where only 828 ESWD reports are available during the investigation period compared to 3022 for Germany (note that most of the hailstorms are captured by various reports). Furthermore, an unknown part of the SCS events is accompanied only by small hail (less than $2 \mathrm{~cm}$ ), which is not reported in the ESWD, or even just by heavy rainfall. Nevertheless, this sample size is still sufficient for the investigation of environmental conditions for different intensity classes.

\subsection{Spatial distribution of SCS and HS events}

The frequency of both SCS and HS events shows a rather high spatial variability but also some larger contiguous spatial patterns. In general, their frequency is lowest near the coast and highest inland. Most pronounced is the large hotspot of SCS events southeast of the center of France near the Massif Central. Other hotspots of SCS and HS events can be found in southwestern Germany between the Black Forest and Swabian Jura or in the southeast near the Ore Mountains. Given a southwesterly flow direction usually predominant on hail-prone days in both France and Germany (Vinet, 


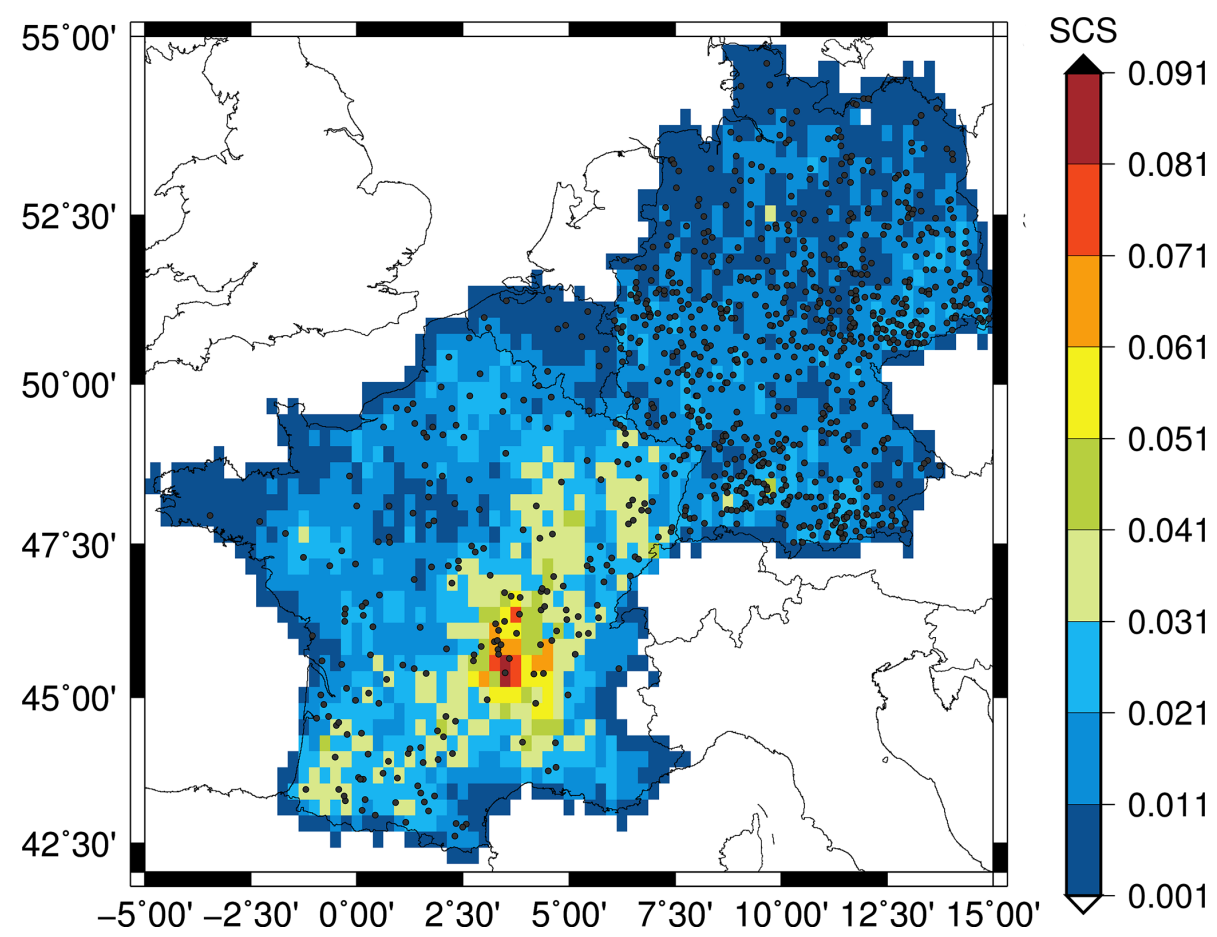

Figure 1. Number of SCSs per year (center of each track) interpolated at $0.25^{\circ} \times 0.25^{\circ}$ (color bar) and HSs (black dots) between 2005 and 2014 over the investigation area (France, Germany, Belgium, and Luxembourg).

2001; Kunz and Puskeiler, 2010; Piper et al., 2019), most of these hotspots are located over and downstream of the mountain ranges. Over France, SCS tracks are much more frequent compared to Germany (Fig. 1). By contrast, HS tracks are far more frequently detected over Germany due to more available reports. Nevertheless, Fig. 1 suggests a relationship between the two records: regions with an increased SCS frequency also show an increased HS frequency and vice versa.

\subsection{Daily and seasonal cycle}

Both HS and SCS events (the latter not shown) feature pronounced seasonal and diurnal cycles with a maximum in the afternoon in the warmest months of July and August. While the number of HSs is lowest in April and September and dominated by smaller-sized hail, the months of May to July are similar with the highest number of HS events of the diameter class $D \geq 5 \mathrm{~cm}$ in June (Fig. 2a). A comparison of the 3 summer months shows that events with large hail are rarest in July. Reasons for this counterintuitive result might be a decrease in frontal events, which have low hail sizes on average (cf. Sect. 2.5.1), or reduced reporting in this month due to summer vacations.

The diurnal cycle is much more pronounced than the seasonal cycle. The minimum number of HS events occurs in the early morning hours between 03:00 and 09:00 LT, and the maximum is in the afternoon between 15:00 and 18:00 LT (Fig. 2b). The largest increase occurs between 12:00 and
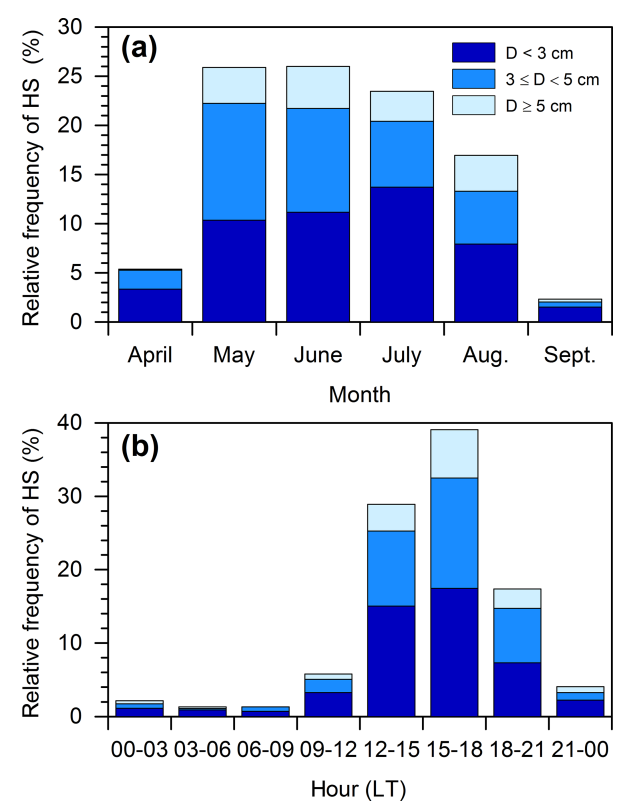

Figure 2. (a) Seasonal and (b) diurnal (local time; LT) cycle of HS tracks (SHY of 2004-2014) depending on the hail size diameter according to ESWD reports. 
15:00 LT, and the largest decrease is after 21:00 LT. A total of 841 events, which correspond to $85.4 \%$ of the HS sample, are registered in the period from 12:00 to 21:00 LT.

A separation of the diurnal cycle according to the hail diameter shows that during the first half of the day (00:0012:00 LT), most events are associated with hail smaller than $5 \mathrm{~cm}$. Especially from 03:00 to 09:00 LT, hailstones are the smallest of the entire day. This result, however, must be treated with care because of the low number of events in that period (26 events) in combination with the potential underreporting by spotters in the night. During noon and afternoon, the proportion of hail with a diameter of at least $5 \mathrm{~cm}$ increases, and the highest probability of occurrence is between 15:00 and 18:00 LT. In the evening and night (18:0000:00 LT), the relative proportion of large hail remains almost constant.

The pronounced diurnal cycle of the HS probability (Fig. 2b) is closely linked to the warming of near-surface layers of air and the associated increase in lapse rate and CAPE together with a decrease in CIN (Markowski and Richardson, 2010). In addition, triggering mechanisms such as low-level flow convergence in the wake of thermally induced circulation over complex terrain or inhomogeneities in land cover are also connected to the diurnal temperature cycle. Studies using radar reflectivity or lightning detections found similar diurnal cycles for most of the area except for the Mediterranean (e.g., Wapler, 2013; Nisi et al., 2016; Piper and Kunz, 2017).

\section{SCSs associated with synoptic cold fronts}

Because of their relevance for SCS triggering, we investigate in the following the relation between synoptic cold fronts with a significant length typically associated with extratropical cyclones and SCS or HS events. Warm fronts are not considered here because they are not important triggers for convection. This is mainly due to their reduced cross-frontal circulation and the resulting slow ascend, deduced through the Sawyer-Eliassen equation (Emanuel, 1985), in combination with warm-air advection aloft, which has a stabilizing effect. Because of their limitation to a specific territory, we also do not consider regional-scale land-sea contrasts, seabreeze fronts, and thermal boundaries from Alpine pumping in the analysis.

\subsection{Cold-front climatology}

The investigation area is frequently affected by synopticscale cold fronts. The number of fronts per grid point of the size $1^{\circ} \times 1^{\circ}$ during the 10 -year investigation period ranges between 85 in eastern Germany and 175 near the Pyrenees (Fig. 3). Overall, front density in France is larger than in Germany.
During their propagation, cold fronts tend to weaken over land mainly because of friction in the lowest layers and the horizontal mixing of air mass properties. Usually, they also dissolve when the air from the warm sector has entirely lifted (occlusion). As the largest fraction of fronts affecting central Europe propagates in eastern to southeastern directions, their detectable density gradually decreases in the same direction. In addition, an elevated front density can be found on the western and northern side (upstream) of large mountains such as the Pyrenees, Massif Central, and the Alps. These large mountain ranges tend to slow down the propagation of fronts, leading to an elevated frequency upstream when counting the time steps where a front prevails (Schemm et al., 2016). Thus, slowly propagating fronts may be repeatedly detected and counted during the time steps of ERA-Interim $(6 \mathrm{~h})$. In contrast, fronts occur less frequently downstream of larger mountains as well as at a greater distance to the sea, where the increasing continentality acts to weaken or even dissolve the fronts.

\subsection{Occurrence of frontal SCS and HS tracks}

To assess the role of synoptic cold fronts in the probability and properties of SCSs, we first discuss the spatial distribution of the ratio of frontal SCSs relative to all SCS events. This ratio is computed independently for each single grid point with a size of $0.5^{\circ} \times 0.5^{\circ}$. Averaged over the entire area of Germany and over the 10 -year study period, $18.9 \%$ of all SCS tracks are related to a cold front; for France, the ratio is slightly higher with $22.4 \%$ (Fig. 4). The most conspicuous feature in the spatial distribution of the frontal streaks is the strong gradient in the south-to-north direction, particularly over Germany. For example, while in the German northeast (Mecklenburg Lake Plateau) the share of frontal SCSs reaches the highest value of $50 \%$, it decreases to less than $10 \%$ in southern Germany over the Black Forest (southwestern Germany) and the region south of Nuremberg (southeastern Germany). Most striking in France is the extended maximum of the frontal share of around $45 \%$ northeast of the domain's center and several minima with only a few percent near the coasts of both the North Atlantic and the Mediterranean.

If we compare the proportion of frontal SCSs both with the distribution of all SCS tracks (Fig. 1) and with the frontal density (Fig. 3), the opposite behavior is often observed. In several regions with an increased number of fronts and/or SCS events, the number of frontal SCSs is low and vice versa. This is especially true for Germany but also for parts of France. Over complex terrain such as in southwestern Germany (Black Forest) or southern France (Massif Central), where frontal SCSs are comparatively rare, it can be assumed that orographically induced vertical lifting is often sufficient to trigger convection so that a front is not necessary.

Considering HS instead of SCS events, we found that an even higher number, namely $25 \%$ of all HS tracks across the 


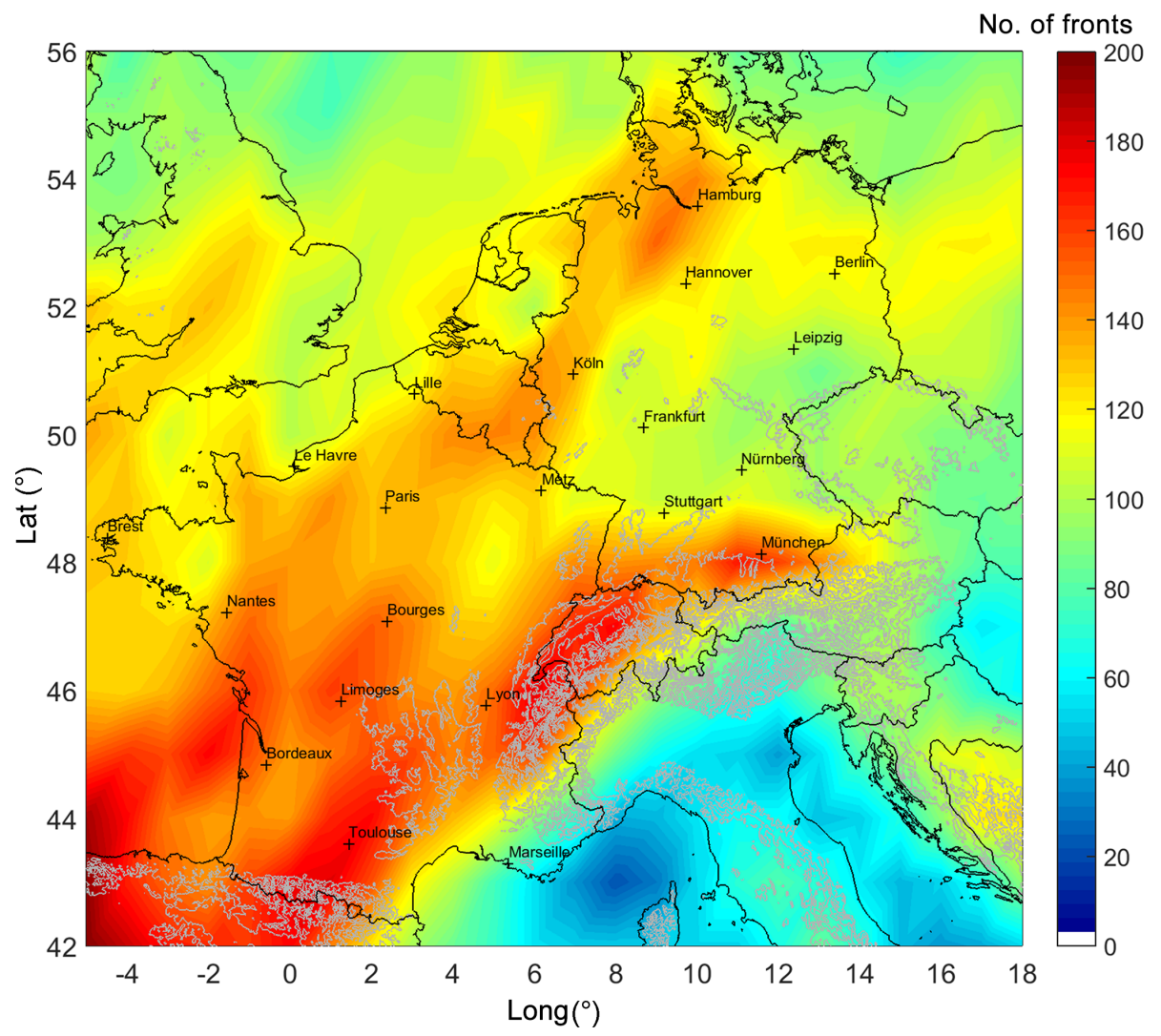

Figure 3. Number of synoptic-scale fronts per $1^{\circ} \times 1^{\circ}$ area between 2005 and 2014 (SHY) based on the ERA-Interim reanalysis according to Schemm et al. (2015). Grey isolines represent the terrain $(600,1200,1800$, and $3600 \mathrm{~m}$ a.s.1.). Please note that the cities in this figure are presented in their local names.
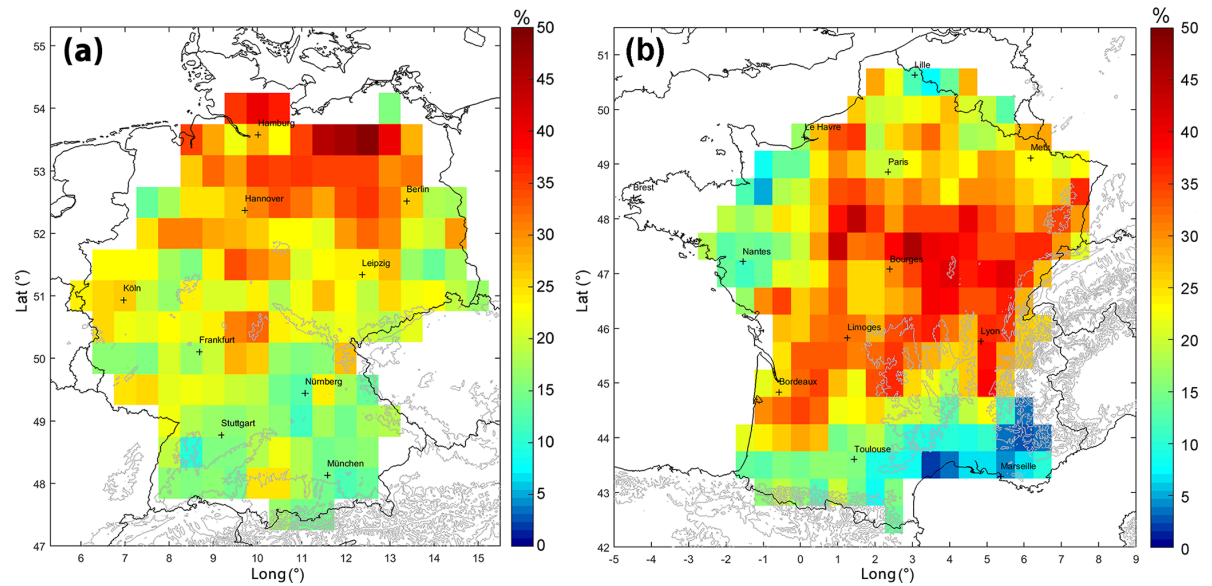

Figure 4. Share of frontal SCSs (relative to all SCSs; $r \leq 200 \mathrm{~km}$ ) over (a) Germany and (b) France for $0.5^{\circ} \times 0.5^{\circ}$ (SHY of 2005-2014). Grid points containing less than 50 SCS tracks (see Fig. 1) were left white. Please note that the cities in this figure are presented in their local names.

entire study domain, are connected to a synoptic cold front. Because of the small number of HS track detections, especially in France (cf. Fig. 1), we do not show this relation here. Note, however, that if only areas with a sufficient number of events are considered, the spatial distributions of frontal HS and SCS tracks are quite similar.

For the HS events, a relation is found between the length of the tracks as detected by the radar algorithm and the maximum observed hail diameter (Fig. 5a). While the mean 

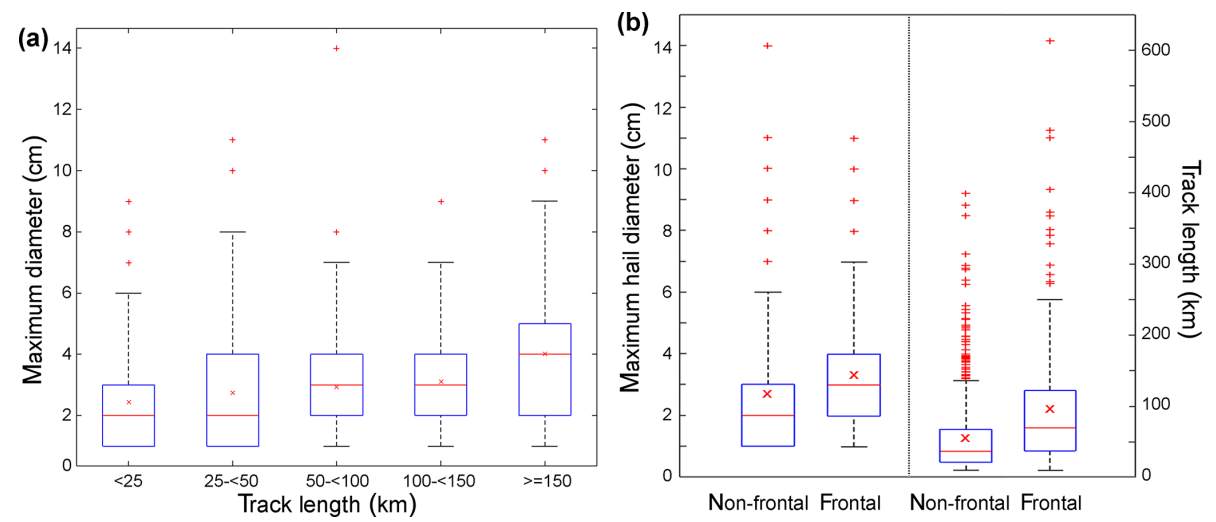

Figure 5. Boxplots showing (a) HS track lengths vs. maximum hail diameter according to ESWD reports and (b) maximum diameter (left) and track length (right) for HS events with or without a synoptic-scale cold front. Indicated in the boxplots are the interquartile range (blue box), median and mean values (red line and red $\mathrm{x}$ ), and upper and lower $25 \%$ percentile \pm interquartile range $\times 1.5$ (black lines); data points outside of this range are marked as outliers (red crosses).

diameter for a length of $L<50 \mathrm{~km}$ is around $2 \mathrm{~cm}$, it increases to around $3 \mathrm{~cm}$ for $50 \geq L<150 \mathrm{~km}$ and to $4 \mathrm{~cm}$ for $L \geq 150 \mathrm{~km}$. Furthermore, the distributions of both quantities, maximum diameters and track lengths, differ between frontal and non-frontal streaks. Mean diameters are $3.3 \mathrm{~cm}$ in for frontal events and $2.73 \mathrm{~cm}$ for the others (Fig. $5 \mathrm{~b}$, left). For hail size diameter classes of $<2,2-3.5,4-5.5$, and $\geq 6 \mathrm{~cm}$, the ratio between frontal and non-frontal events is $16.7 \%, 23.1 \%, 35.8 \%$, and $34.7 \%$, respectively (not shown; note that the finer classes are used only in this example). This means that the higher the probability of a nearby front is, the larger the hailstone diameter is on average.

Differences between frontal and non-frontal HS events are also found for the length and mean propagation direction of the tracks. While frontal HS tracks have a mean length of $96.2 \mathrm{~km}$ (interquartile range of $40-125 \mathrm{~km}$ ), nonfrontal tracks are almost half shorter with $56.8 \mathrm{~km}(25-$ $65 \mathrm{~km}$; Fig. $5 \mathrm{~b}$, right part). Non-frontal HS events have a mean propagation angle of $215^{\circ}$ (interquartile range 185$255^{\circ}$ ), whereas those connected to a front propagate slightly more to the east with a direction of $232^{\circ}$ (interquartile range $217-258^{\circ}$; not shown). In that latter range of angles, also the largest hailstones can be observed.

\section{Environmental conditions of HS tracks}

Environmental conditions prevailing during HS events are investigated using SLI, DLS, and SRH from the ERA-Interim reanalysis (see Sect. 2.2). The composites presented in the following show the mean fields of the respective parameter around the center of the HS tracks (see Sect. 2.5.3). To examine environmental conditions depending on the intensity of the HS events, we further divided the HS sample into nine subsamples according to the observed hail diameter $D(<3$, $3-4$, and $\geq 5 \mathrm{~cm})$ and track length $L(<50,50-100$, and
Table 1. Number of HS events in the respective classes of maximum hail size diameter $D$ and track length $L$

\begin{tabular}{lrrc}
\hline & $L<50 \mathrm{~km}$ & $L=50-100 \mathrm{~km}$ & $L>100 \mathrm{~km}$ \\
\hline$D<3 \mathrm{~cm}$ & 311 & 98 & 64 \\
$D=3-4.5 \mathrm{~cm}$ & 190 & 102 & 72 \\
$D \geq 5 \mathrm{~cm}$ & 63 & 35 & 50 \\
\hline
\end{tabular}

$>100 \mathrm{~km})$. When defining the threshold values, it was taken into account that each class contains at least 50 events - except of the class $L=50-100 \mathrm{~km}$ and $D \geq 5 \mathrm{~cm}$ (Table 1 ). Using other thresholds, for example, $150 \mathrm{~km}$ instead of $100 \mathrm{~km}$ as suggested by the diameter-length relation shown in the boxplot (Fig. 5), would result in sample sizes which were too small with less than 30 events. A further subdivision, for example, according to the time of occurrence, was not carried out. Although scientifically interesting, this would further reduce the sample sizes, particularly the most interesting highintensity classes.

\subsection{Mean composites of environmental conditions}

Averaged over all classes of HS events, SLI around the center of the tracks has a mean value of $-3.8 \mathrm{~K}$ (Fig. 6a), indicating a high potential for convective storms (e.g., Manzato, 2003; Kunz, 2007). SLI has its absolute minimum about $140 \mathrm{~km}$ southeast of the events, but the difference to the center, on average of $0.2 \mathrm{~K}$, is almost negligible. Overall, a significant increase in convection-favoring conditions can be observed from the northwest of the HS center to the southeast. While these conditions prevail over $400 \mathrm{~km}$ to the south and east of the center, the area to the north and west sees higher and positive values of SLI, thus stable conditions, at approximately $100-200 \mathrm{~km}$ distance already. The SLI field occurs 
rather smooth mainly because of the low resolution of ERAInterim (cf. Sect. 5.3).

The vertical wind shear (DLS) has its maximum about $250 \mathrm{~km}$ to the west of the HS centers in an upstream direction (Fig. 6b). This spatial difference is plausible because a trough frequently prevails to the west of the events. Since DLS is dominated by the wind speed aloft $(500 \mathrm{hPa})$, a trough with an associated jet manifests itself by a maximum in DLS. Considering the magnitude of DLS, it is found that the values are quite low with a mean of $12.5 \mathrm{~m} \mathrm{~s}^{-1}$ around the HS events. Several authors have shown that organized convection capable of producing larger hail develops only in sheared environments above around $10 \mathrm{~m} \mathrm{~s}^{-1}$ (e.g., Weisman and Klemp, 1982; Markowski and Richardson, 2010; Dennis and Kumjian, 2017). This is one of the reasons to further subdivide the whole sample as mentioned above and shown in the next paragraph.

\subsection{Environmental conditions depending on hail size and track length}

Separating the hail events according to their intensity allows for a detailed view of the prevailing environmental conditions. The SLI composites show a slight decrease (higher instability) around the center of the HS events from small hail with shorter tracks $(\mathrm{SLI} \approx-3.7 \mathrm{~K}$ ) to large hail with longer tracks (SLI $\approx-4.5 \mathrm{~K} ;$ Fig. 7). The strongest decrease in stability occurs for increasing hail diameter, while the composites are less sensitive to variations in track lengths. In all cases, the lowest instability prevails to the southeast of the hail events as was already found for the mean composite (cf. Fig. 6). Despite favorable environments for SCSs, which predominate all classes, the highest instability in the case of larger hail is an indicator of higher updraft speed within the thunderstorm cloud, which is a prerequisite for the growth to large hailstones.

The distance between the location of the events and the location of the highest instability is greater for longer tracks than for shorter ones but only in the case of small- to medium-sized hail. At this point one may speculate that the reason for this shift might be related to the role of cold fronts, considering that longer tracks and larger hailstones are more often connected to a cold front as discussed in the previous section (cf. Fig. 5). The role of cold fronts vs. environmental conditions will be investigated in the next section.

In contrast to the thermodynamical proxy SLI, the dynamical quantity DLS shows significantly pronounced differences between the nine HS categories (Fig. 8). Even though DLS also distinguishes between the diameter classes, the largest differences are found for the three length classes. For example, DLS has a mean value of $17 \mathrm{~m} \mathrm{~s}^{-1}$ for long tracks in the smallest diameter class $(D<3 \mathrm{~cm})$, which is almost twice as high compared to short tracks with the same diameter class ( $8.5 \mathrm{~m} \mathrm{~s}^{-1}$; Fig. 8 , upper row). The same applies to the other diameter classes. For long tracks with large hail, DLS reaches values of about $20 \mathrm{~m} \mathrm{~s}^{-1}$ and is thus in the range of the values given in the literature (e.g., Weisman and Klemp, 1982; Thompson et al., 2007; Markowski and Richardson, 2010). The area of the highest DLS values is located several hundred kilometers to the west of the HS events on average. For large hail, the DLS maxima are even higher and further away from the HS events. These events are usually triggered by upper-level troughs to the west, associated with higher wind speed at mid-troposphere levels. One may argue that a relationship between DLS and track length prevails per se, since both are dominated by the wind speed aloft. Note, however, that the separation of DLS applies not only to track length but also to storm duration (not shown here, but see Wandel, 2017).

In addition to DLS, SRH has been suggested by several authors (e.g., Thompson et al., 2007; Kunz et al., 2018) to be an important proxy not only for the prediction of tornadoes but also for large hail. In our composite analyses, SRH (Fig. 9) shows even more pronounced differences between the nine HS categories compared to DLS. Hail events with shorter tracks on average are in a range between 0 and $50 \mathrm{~m}^{2} \mathrm{~s}^{-2}$. By contrast, longer tracks have much higher mean values between 84 and $116 \mathrm{~m}^{2} \mathrm{~s}^{-2}$. According to the investigations of proximity soundings by Thompson et al. (2007), such environments favor the development of weakly tornadic and nontornadic supercells - provided that sufficient CAPE is present. In addition, there is also an increase in SRH from small to large hail, which is weaker compared to the trend in the length classes. Interestingly, the highest SRH values occur directly at or near the location of the hail event and not on the upstream side as was the case for DLS.

To further investigate which of the dynamical parameters, SRH or DLS, best distinguishes the HS intensity, we consider only the two categories that correspond to the highest and lowest damage potentials: smaller hail with $D<3 \mathrm{~cm}$ combined with short track length of $L<50 \mathrm{~km}$ and large hail with $D \geq 5 \mathrm{~cm}$ combined with longer tracks of more than $100 \mathrm{~km}$ (high-intensity events). Environmental parameters are computed by the mean of the $3 \times 3$ ERA-Interim grid points centered around the HS locations.

Overall, the scatterplots presented in Fig. 10 show a much clearer separation between the events when SRH is considered (Fig. 10a) instead of DLS (Fig. 10b). About $50 \%$ of the high-intensity events have values of $100 \mathrm{~m}^{2} \mathrm{~s}^{-2}$ or greater for SRH, while only $3 \%$ of the low-intensity events display these values. Furthermore, most of the latter events have values between -50 and $50 \mathrm{~m}^{2} \mathrm{~s}^{-2}$. It can also be seen that SLI for all events in these two categories varies between 0 and $-10 \mathrm{~K}$, with only a few exceptions having positive values. Approximately $70 \%$ of the high-intensity events have values of $-2.5 \mathrm{~K}$ or less. Unlike DLS (Fig. 10b), splitting the events into two different categories is not possible. Even if most of the high-intensity events form in an environment with DLS of at least $15 \mathrm{~m} \mathrm{~s}^{-1}$ (approx. $60 \%$ of these events), there are still many low-intensity events for larger DLS values. 

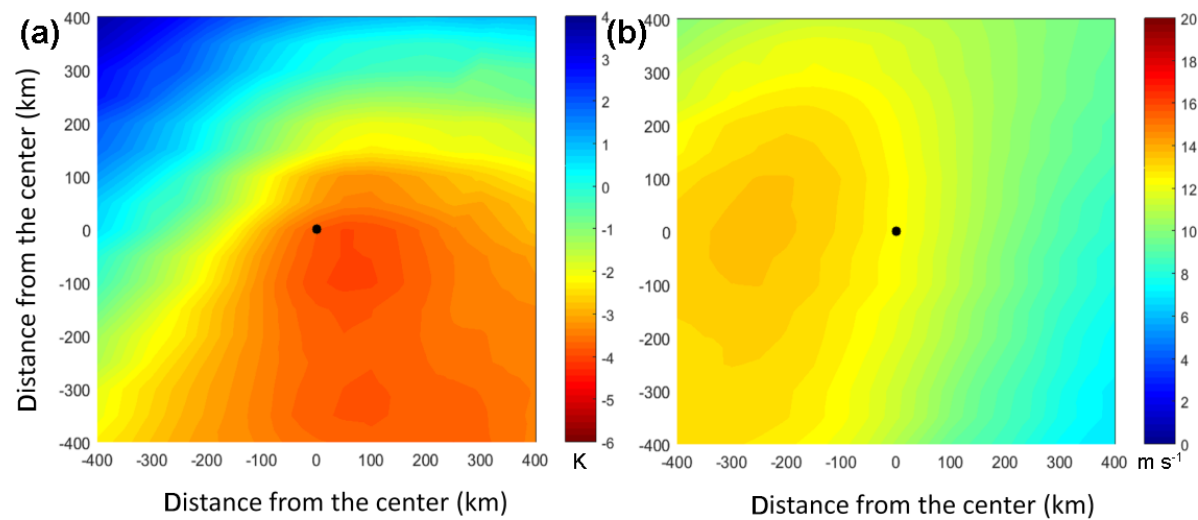

Figure 6. Composite analyses showing the average values of (a) SLI and (b) DLS from ERA-Interim in moving spatial windows centered at the track location (center) for all 985 HS events between 2005 and 2014 (SHY; see Fig. 1).
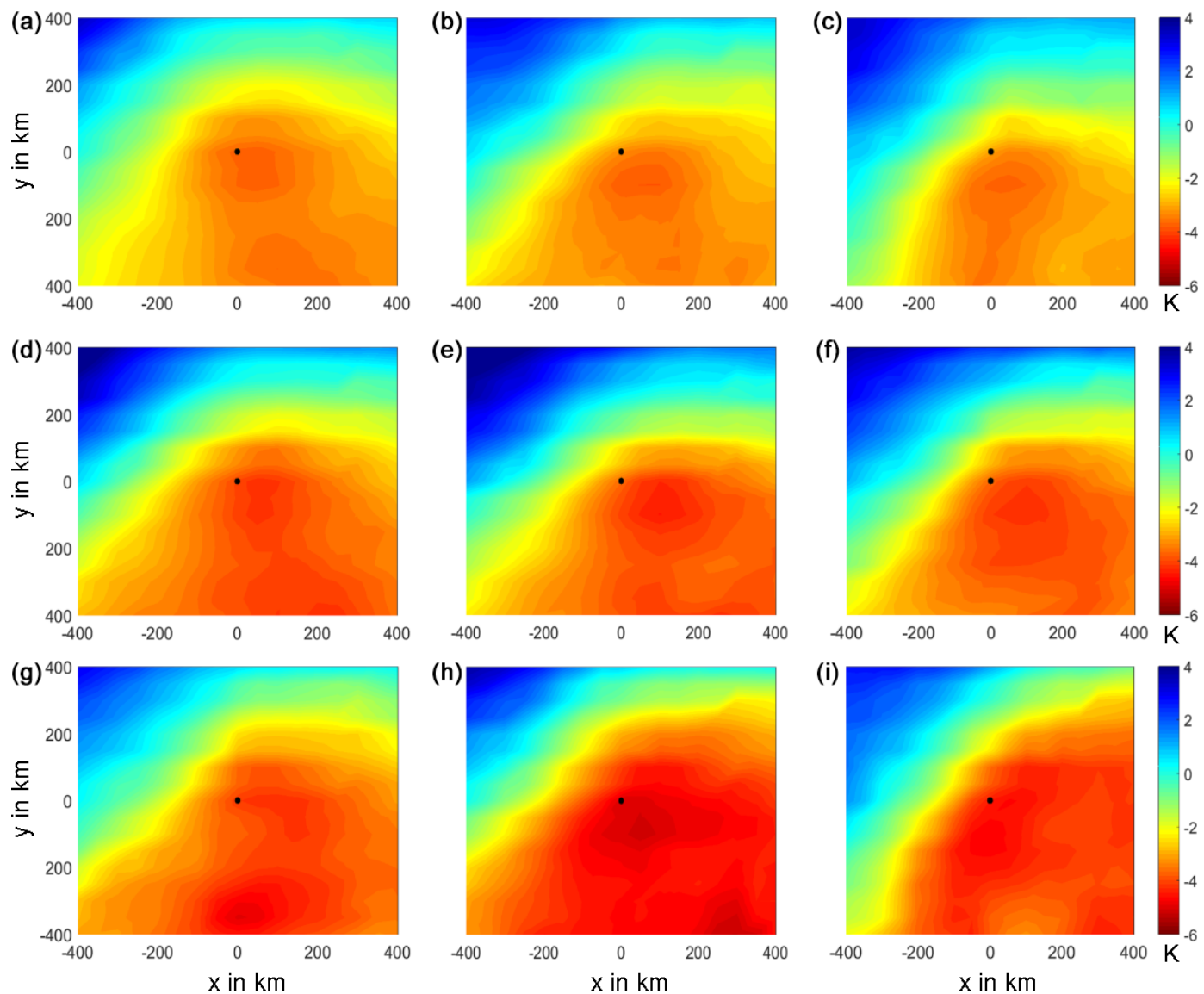

Figure 7. Composite analyses of SLI related to maximum observed hail diameters of $D<3 \mathrm{~cm}(\mathbf{a}-\mathbf{c}), 3-4.5 \mathrm{~cm}(\mathbf{d}-\mathbf{f})$, and $\geq 5 \mathrm{~cm}(\mathbf{g}-\mathbf{i})$ and for track lengths of $L<50 \mathrm{~km}(\mathbf{a}, \mathbf{d}, \mathbf{g}), 50-100 \mathrm{~km}(\mathbf{b}, \mathbf{e}, \mathbf{h})$, and $\geq 100 \mathrm{~km}(\mathbf{c}, \mathbf{f}, \mathbf{i})$. The sizes of the subsamples are listed in Table 1 .

\subsection{Effects of model resolution on convective parameters}

Subgrid-scale spatial variations of the environmental conditions, for example, as a result of diabatic heating or temperature and moisture advection (Markowski and Richardson,
2010), cannot be expected to be reproduced by the coarse ERA-Interim reanalysis. For this reason, we additionally considered the high-resolution coastDat-3 reanalysis. Due to the hourly resolved model fields, the maximum time difference between the HS events and the environments is $30 \mathrm{~min}$. The purpose is not to reproduce the above analyses but to in- 

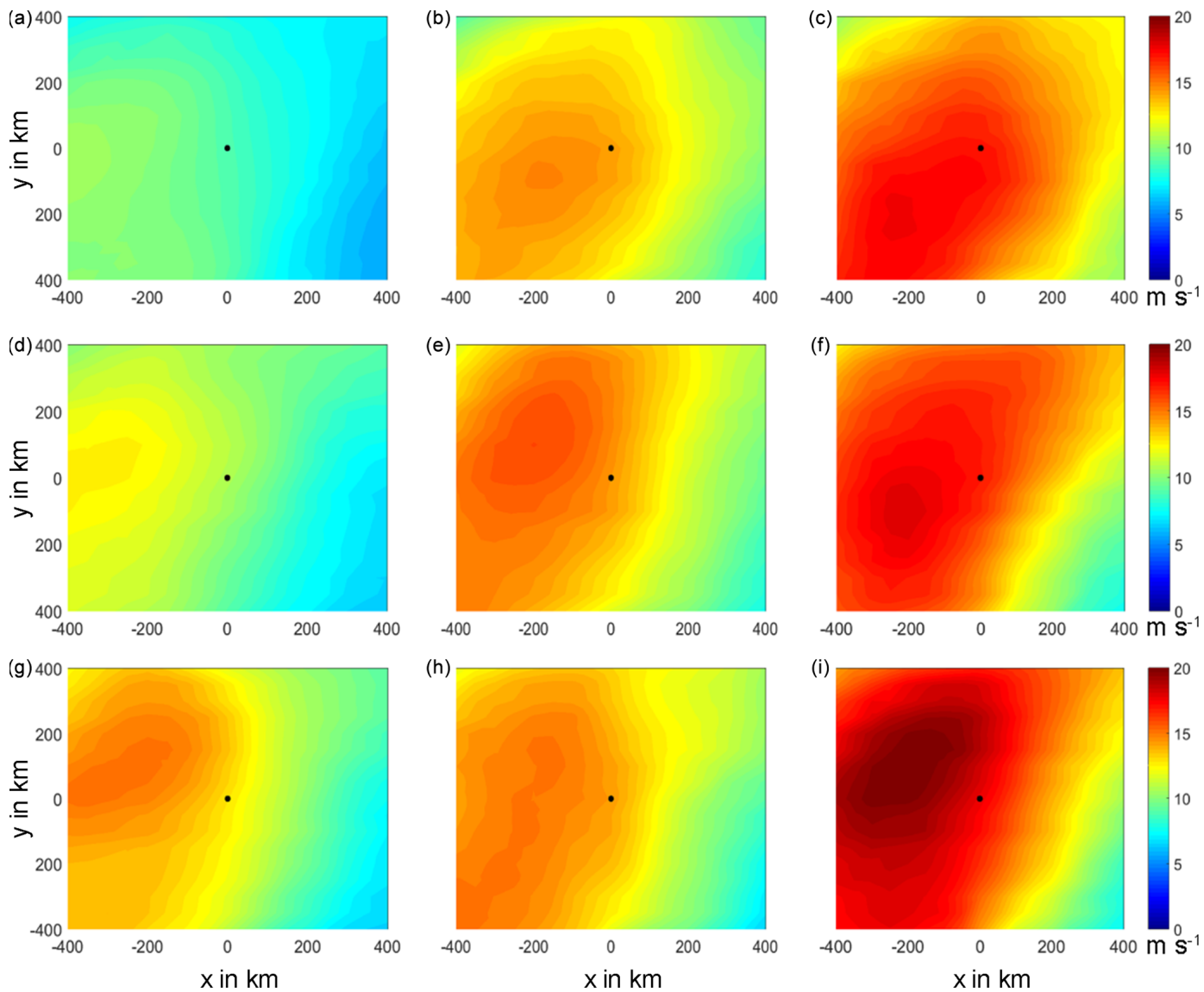

Figure 8. Same as Fig. 7 but for $0-500 \mathrm{hPa}$ DLS.

vestigate exemplarily the influence of the model resolution on the results. Since SLI and SRH are not available or quantifiable from coastDat-3, we used LR as a thermodynamical proxy and DLS as a dynamical proxy (cf. Sect. 2.2). Because the two proxies do not show significant differences between the nine intensity categories (cf. Figs. 7 to 9), we discuss only the most severe HS category with $L \geq 100 \mathrm{~km}$ and $D \geq 5 \mathrm{~cm}$.

As shown in Fig. 11, the higher model resolution (right column) has little influence on the spatial distribution of the environmental parameters even though coastDat-3 composites show a much larger spatial variability compared to ERAInterim. In the case of LR, the maximum is located to the southwest; in the case of DLS, it is located northeast of the HS events as was already found in the above analyses. Also the distance between the maxima and the events remains almost the same. The coastDat-3 values around the maxima show a slight increase of approximately $10 \%$ for both parameters. In the vicinity of the HS centers, the increase is only marginal but larger for LR compared to DLS. In particular the LR increase is a consequence of the higher temporal resolution of coastDat-3 leading to an improved representation of the diurnal temperature and moisture cycles. Note that this finding does not only apply to LR but also to other thermodynamic quantities such as the precipitable water (not shown).

\subsection{Frontal vs. non-frontal HS tracks}

As already discussed in Sect. 4.2, the characteristics of HS tracks having a front nearby substantially differ from non-frontal events, especially with regard to the maximum hail size and the track lengths (cf. Fig. 5). This suggests that prevailing environmental conditions may likewise differ for the two kinds of events. Therefore, we further subdivided the HS sample into frontal and non-frontal types. To ensure that enough events enter the subsamples, we made a further separation by considering only two length classes $(L<75$ and $\geq 75 \mathrm{~km})$ and two diameter classes $(D<3$ and $\geq 3 \mathrm{~cm}$; the former not shown).

Whereas the mean SLI composites are almost similar for frontal and non-frontal events (not shown), DLS shows significant differences between the four classes (Fig. 12). Overall, DLS reaches higher values with larger gradients for frontal compared to non-frontal events (Fig. 12, panels a and c vs. b and d). However, when considering additionally the track lengths, much larger differences in DLS can be found, but only for non-frontal events (Fig. 12b and d). While 

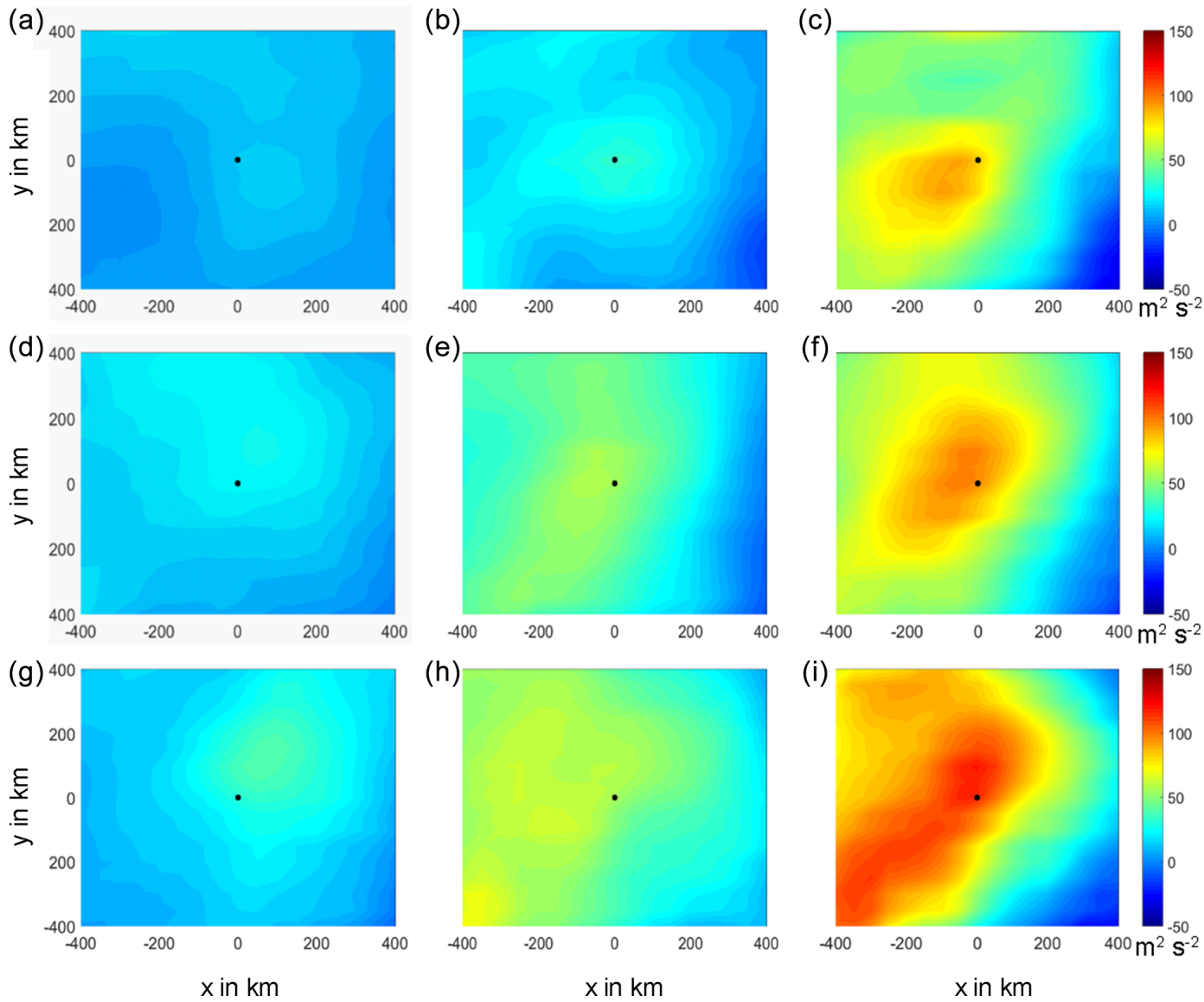

Figure 9. Same as Fig. 7 but for $0-3 \mathrm{~km} \mathrm{SRH.}$
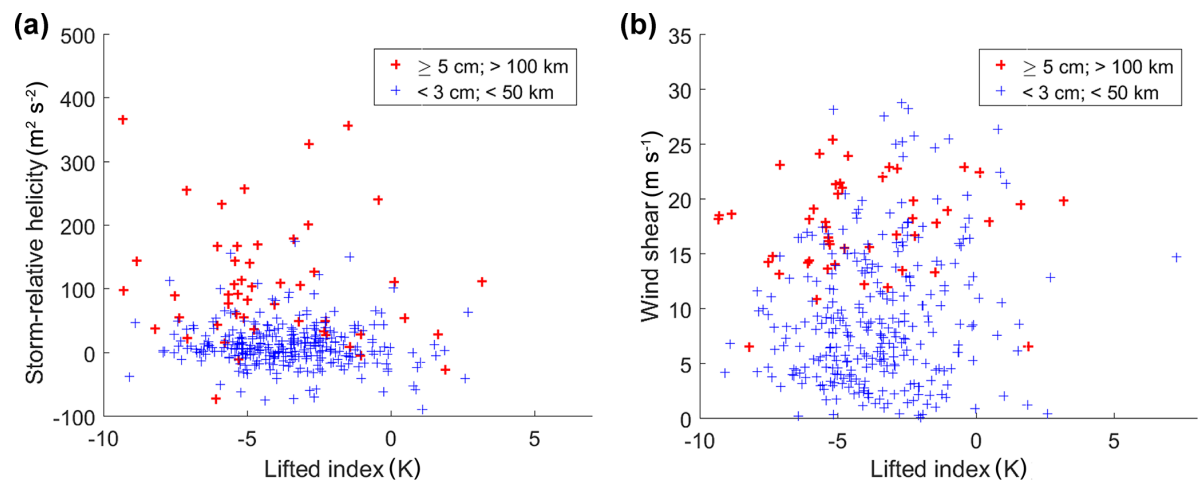

Figure 10. Scatterplots between (a) SLI and SRH and (b) DLS for two different categories of track length and hail diameter.

short non-frontal tracks form at a DLS value of $10.9 \mathrm{~m} \mathrm{~s}^{-1}$ on average, long tracks require medium-sheared environments, here with values of $15.9 \mathrm{~m} \mathrm{~s}^{-1}$. A similar result is obtained for small hail sizes $(D<3 \mathrm{~cm})$ with DLS even rising from 9.0 to $16.7 \mathrm{~m} \mathrm{~s}^{-1}$ (not shown). Furthermore, while the DLS maximum for non-frontal events is located to the west of the center, it is more northwest for frontal events at a distance of about $200 \mathrm{~km}$. Since almost all synoptic fronts in Europe propagate in a west-east direction, this location is a clear indication that frontal HS events preferably develop in prefrontal environments (and not postfrontal).

\subsection{Differences in wind direction}

It is well-known that supercells due to specific conditions, such as a strong and spatially extended updraft, high amounts of supercooled liquid water, or their longevity, are capable to produce the largest hailstones (Foote, 1984; 

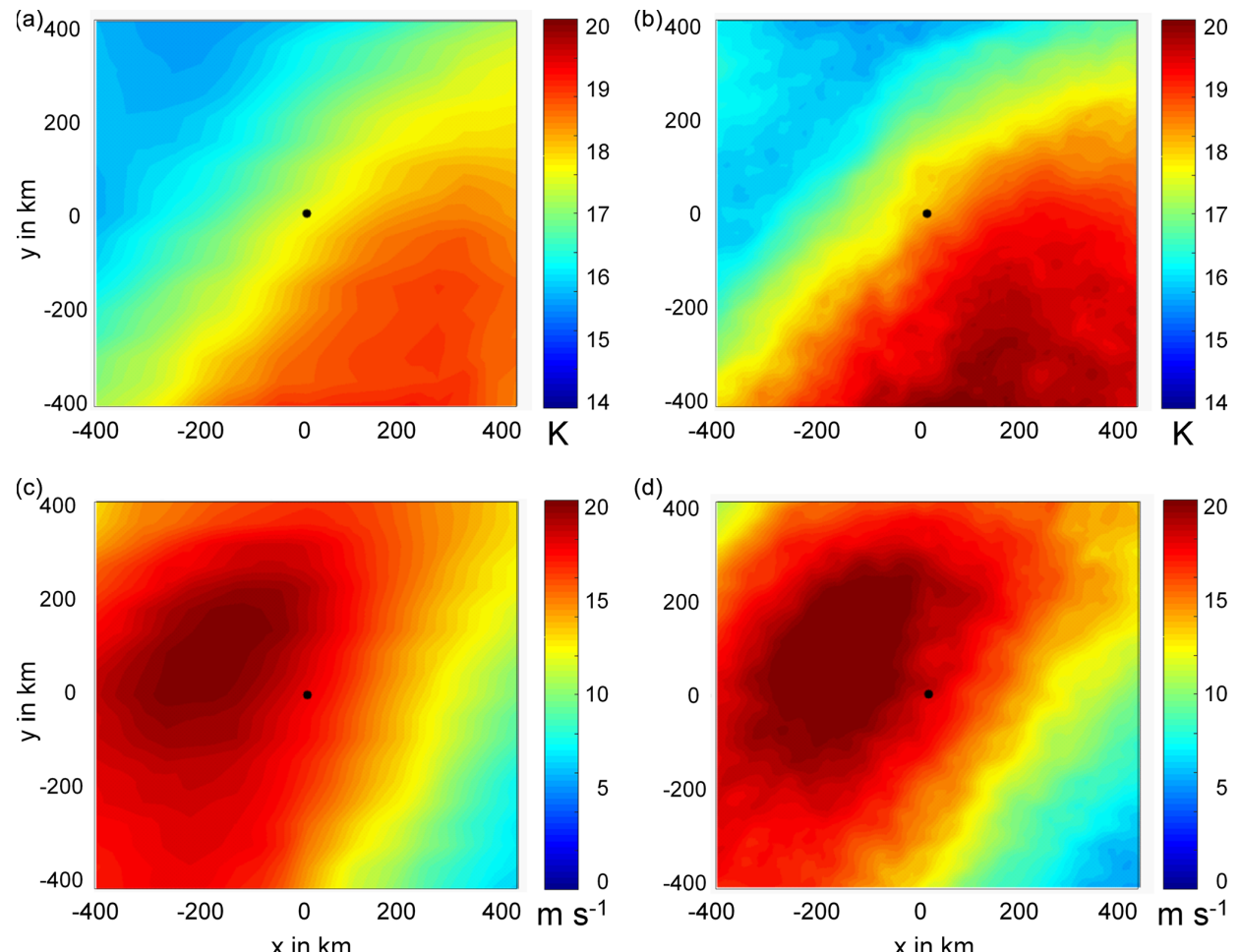

Figure 11. Composites of LR (a, b) and DLS (c, d) for hail diameters $D \geq 5 \mathrm{~cm}$ and track lengths $L \geq 100 \mathrm{~km}$ based on ERA-Interim (a, c) and coastDat-3 $(\mathbf{b}, \mathbf{d})$ reanalyses.
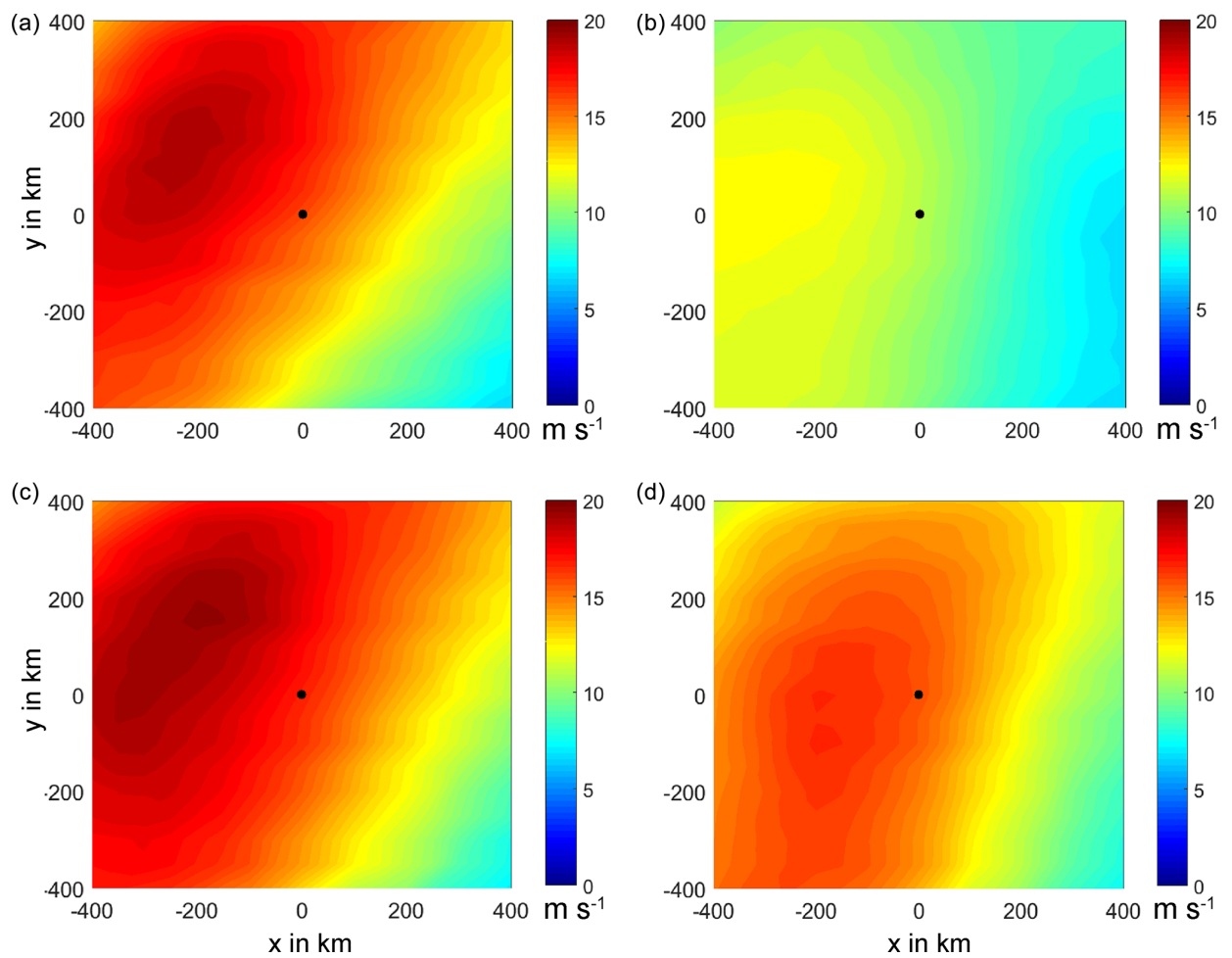

Figure 12. Composites of DLS for maximum observed hail diameters $D \geq 3 \mathrm{~cm}$ and track lengths of $L<75 \mathrm{~km}(\mathbf{a}, \mathbf{b})$ and $L \geq 75 \mathrm{~km}(\mathbf{c}, \mathbf{d})$ for frontal (a, c) and non-frontal (b, d) HS events. 
Markowski and Richardson, 2010; Dennis and Kumjian, 2017). The propagation of these highly organized convective systems can substantially deviate from the horizontal wind at mid-tropospheric levels mainly because of the dynamics of the cold pools and induced vertical pressure deviations (Markowski and Richardson, 2010).

In the last step, therefore, we want to investigate whether our samples show a relation between the storm motion relative to the mean wind and the hail size. The storm motion vector $\boldsymbol{c}$ follows from the radar tracking of the individual HS events; the wind direction is estimated from the $500 \mathrm{hPa}$ mean wind from ERA-Interim $(3 \times 3$ grid point around the HS centers). The cell-tracking algorithm (cf. Sect. 2.4) yields very reliable shift vectors of individual hailstorms. The wind field in $500 \mathrm{hPa}$, on the other hand, is mainly determined by the setting of the synoptic systems and only marginally affected by local-scale flow deviations. Positive differences in the analyses indicate right-moving storms; negative values indicate left-moving storms.

Most of the events with smaller hail $(D<3 \mathrm{~cm})$ propagate approximately parallel to the wind vectors in $500 \mathrm{hPa}$; the mean difference between the tracks and the wind vectors is only $8^{\circ}$ (Fig. 13a). About $13 \%$ of all HS events have a deviation between 30 and $60^{\circ}$ to the right, while only $6 \%$ of the events show deviations to the left for this interval $(-30$ to $\left.-60^{\circ}\right)$. Hail events with maximum diameters between 3 and $4.5 \mathrm{~cm}$ show a deviation of the propagation direction preferably to the right of the wind vectors (Fig. 13b); $23 \%$ of all HS events propagate with the wind in $500 \mathrm{hPa}$ (decreasing by $8 \%$ compared to small hail), while $38 \%$ of the tracks show a deviation between 10 and $30^{\circ}$.

HS events of the largest hail class not only show an increased spread of the propagation deviation but also the entire histogram is shifted to more right-moving storms (median of $17^{\circ}$; Fig. 13c). An angle difference between 10 and $30^{\circ}$ is observed for $35 \%$ of all events. The largest difference to the other hail size classes is the comparatively high number of HS events between 30 and $60^{\circ}(21 \%)$. In contrast, $27 \%$ of the events propagate with the wind in $500 \mathrm{hPa}$, and only $10 \%$ have a negative deviation to the left of the wind in $500 \mathrm{hPa}$. In summary, the larger the hailstone diameters are, the stronger the deviation of the cell's propagation direction from the flow at $500 \mathrm{hPa}$ is.

\section{Discussion}

Severe convective storms, chiefly hailstorms, are highfrequent perils that, due to their local-scale nature, affect only small areas (Changnon, 1977). Their reconstruction requires high-resolution observational data such as radar reflectivity used in our study. The results of the analyses show high spatial variability of both SCS and HS events, with a gradual increase with growing distance from the ocean and several hotspots, mainly over and downstream of mountain ranges.
For example, as shown by Kunz and Puskeiler (2010), these hotspots are connected to flow convergence at lower layers in the low-Froude-number regime, when the flow tends to go around rather than over the mountains. Overall, the spatial distribution of SCS or HS events agrees with other studies on that topic considering different datasets such as 3D radar reflectivity (Kunz and Kugel, 2015; Puskeiler et al., 2016; Lukach et al., 2017), a combination of radar data with weather stations (Junghänel et al., 2016), or overshooting top detections from satellites (Bedka, 2011; Punge et al., 2017). This applies also to the detected seasonal and diurnal cycles (Nisi et al., 2016, 2018; Punge and Kunz, 2016). The good quantitative and qualitative agreement is a strong indication of the reliability of our methods and results.

All composites of environment parameters created for radar-derived HS tracks show a similar spatial pattern: whereas the thermodynamic proxies such as SLI have their highest values at some 10 up to $100 \mathrm{~km}$ southeast of the center of the HS events, the maxima of the dynamic proxies (DLS and SRH) are found to the northwest at a distance of 100 to $200 \mathrm{~km}$. This applies to all intensity classes and to all proxies originally considered in our study (also for the $\mathrm{KO}$ index - Konvektiv-Index, convective index - and lapse rate but not for precipitable water - PW, where the maximum is located north of the events).

In total, 651 of the 985 HS events have a southwest-tonortheast propagation direction, reflecting the mean flow direction at mid-troposphere levels. On average, HS events usually occur downstream of the eastern flank of a midtroposphere trough, where southerly-to-southwesterly winds are frequently associated with the advection of unstable, warm, and moist air masses from the Mediterranean (Graf et al., 2011; Wapler and James, 2015; Piper et al., 2019). This constellation is often referred to as "Spanish plume" (Morris, 1986). The trough, on the other hand, creates an environment with increased wind shear and large-scale lifting. The axis of the trough is usually located several hundred kilometers upstream of the HS events, which explains why the highest shear is found on the western flank at larger distances. Furthermore, as convection initiation requires an additional lifting mechanism to overcome the convective inhibition in the planetary boundary layer, the area downstream of a trough is an ideal location for the development of (organized) convection as shown, for example, by Wapler and James (2015), Piper et al. (2019), or Mohr et al. (2020).

The separation of the environmental composites into different classes of hail diameter and track length yields several interesting results. Thermal instability, as expressed, for example, by SLI, increases slightly (smaller values of SLI) from small hail with shorter tracks to large hail with longer tracks, as might be expected. While the strongest decrease is found for increasing hail sizes, the composites are only marginally sensitive to variations in the track length. By contrast, the separation for DLS and SRH is much stronger, particularly for the track lengths. This dependence of the track 

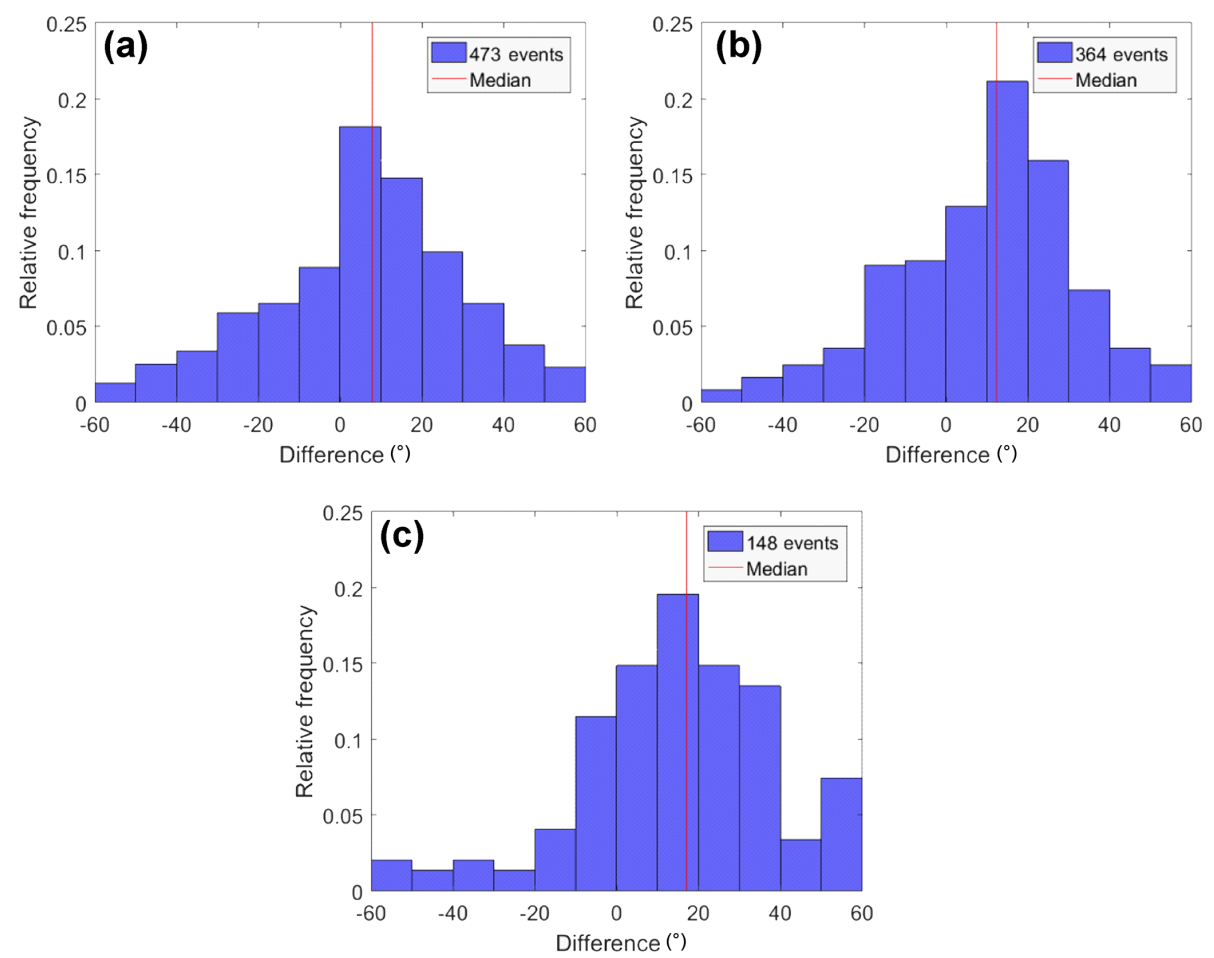

Figure 13. Histograms of HS events showing the relative frequency of the differences in the propagation direction between the storm motion vectors $c$ and the wind in $500 \mathrm{hPa}$ from ERA-Interim at the location and time of the $\mathrm{HS}$ events for three different diameter categories: (a) $D<3 \mathrm{~cm}$, (b) $3 \leq D<5 \mathrm{~cm}$, and (c) $D \geq 5 \mathrm{~cm}$. Median values are indicated by the red line.

lengths to DLS or SRH can be explained plausibly by the storm's organization. Low-to-medium-sheared environments $\left(\leq 10 \mathrm{~m} \mathrm{~s}^{-1}\right)$ permit single cells to develop (Markowski and Richardson, 2010), which are not able to produce large hail. For organized convective storms such as multicells, supercells, or MCSs, substantial shear $\left(>10 \mathrm{~m} \mathrm{~s}^{-1}\right)$ is required, which spatially separates the updraft from the downdraft. Supercell thunderstorms, bearing the largest hailstones, preferably develop in environments with DLS exceeding $18 \mathrm{~m} \mathrm{~s}^{-1}$ (Weisman and Klemp, 1982; Markowski and Richardson, 2010). High-resolution model simulations by Dennis and Kumjian (2017) show that increased DLS upstream elongates the storm's updraft downshear, providing an increased volume of the hailstone growth region, an increased hailstone residence time within the updraft, and a larger region for potential hail embryos. Altogether, these mechanisms lead to increased hail masses and, thus, increased hail diameters, even though the average value of DLS for our event set is at the lower end of the typical value range for multicellular convection.

From the comparison of the two reanalyses, we conclude that ERA-Interim with a comparatively coarse spatial and temporal resolution is suitable to estimate environmental conditions. A higher model resolution is mainly important for estimating thermodynamical parameters, especially those depending on the diurnal temperature cycle. Because the dy- namical environment is not directly connected to the diurnal temperature cycle and therefore does not change much during the day, DLS or SRH, for which our results suggest the closest relation to track length and hail size diameter, can be reliably estimated from low-resolution global models such as ERA-Interim.

The hypothesis that supercells preferably enter the subsample of long tracks and large hail is also supported by the findings of the differences between the propagation vector of cells determined by the tracking algorithm and the mean wind at $500 \mathrm{hPa}$ from the ERA-Interim reanalysis. The larger the hailstones are, the larger the relative share of events with a deviation mostly to the right of the ambient wind is. Because of vertical dynamic pressure perturbations, supercells tend to deviate substantially from the mean wind direction (Markowski and Richardson, 2010). So-called right-moving supercells, usually persisting after cell splitting (Klemp, 1987) because of positive linear dynamic forcing, may deviate from the mean wind direction by angles of up to $30^{\circ}$. Such deviations have already been observed for single supercells in Germany (Kunz et al., 2018). In contrast, multicell thunderstorms or MCSs bearing smaller hailstones show fewer deviations from mid-tropospheric winds.

When a synoptic cold front is involved, the preconvective environment can substantially change on short timescales because of four independent effects (Giaiotti et al., 2003; 
Markowski and Richardson, 2010; Schemm et al., 2016): (i) lapse rate increase by cold-air advection aloft; (ii) vertical lifting by frontal cross circulations, which simultaneously increases CAPE and reduces CIN; (iii) along-front advection of moisture at lower levels leading to an increase in CAPE; and (vi) enhanced curvature of the hodograph related to the thermal-wind equation and, thus, enhanced vertical wind shear. The latter, not directly connected to a front, potentially occurs several hundred kilometers upstream. All the above-listed factors create an environment that favors the development of organized and more persistent thunderstorms, such as multicells and supercells. Therefore, hail events associated with cold fronts are likely to have different properties than non-frontal events. We found, for example, frontal HS events to produce larger hail and longer tracks compared to non-frontal HS events on average. Furthermore, the tracks are strongly coupled to the (typically eastward) propagation of the fronts.

Frontal detection in ERA-Interim is based on some specific criteria such as temperature gradient, minimum length, or propagation speed to consider only significant synoptic fronts. The use of fixed thresholds for these parameters may bring in some bias in the analyses. Especially over and downstream of larger mountain ranges, such as the Massif Central, the Black Forest, or the Alps, fronts can be significantly fragmented or distorted (Löffler-Mang et al., 1996; Dickinson and Knight, 1999) and thus be eliminated by the detection criteria. When interpreting the results of the relationship between fronts and SCS or HS events, it is important to be aware of this limitation. Our purpose was to use an objective identification of fronts, which is valid for the whole study area, and to consider only significant fronts. The share of frontal SCSs (and HSs) to all events substantially varies among the regions. For example, whereas only a limited number of SCSs in southern Germany have a front nearby, almost half of the events over northern Germany are front-related. By combining radar-based hail events for Switzerland between 2002 and 2013 with cold-front detections (Schemm et al., 2015) based on COSMO analysis, Schemm et al. (2016) found that locally up to $45 \%$ of all hail events in northeastern and southern Switzerland are associated with a cold front. This is similar to our study region, where we identified values of up to $50 \%$ locally.

Over complex terrain, it can be assumed that moisture flux convergence at low levels caused by flow deviations at obstacles and local wind systems is the most important trigger mechanism for convection initiation (Weckwerth and Parsons, 2005; Barthlott et al., 2011; Trefalt et al., 2018). In contrast, over mainly flat terrain such as in northern Germany, a front is often required as a trigger for convection. Instability and vertical wind shear are two additional effects that partly determine the probability of frontal SCSs. These two quantities on average are highest in the southern parts of France and Germany, where frontal SCSs are not very frequent. Thus, we conclude that the share of frontal SCSs to all events is the re- sult of the interaction of various influencing factors, mainly of thermal instability and lifting mechanisms to initiate convection.

When a front is nearby, HS events tend to develop east of the maximum of wind shear and northwest of the most unstable stratification. In contrast, non-frontal HS events frequently occur in proximity to the highest wind shear and most unstable conditions. In low-sheared environments, hailstorms capable of producing hail larger than $3 \mathrm{~cm}$ develop only when the air mass is highly unstable. Higher instability, in general, enables stronger updrafts that are required for the development of larger hailstones. For frontal HS events, the stratification remains almost the same, but with the highest instability located more to the southeast of the events. This region of highest instability, however, is characterized by lower shear. At the same time, assuming a trough prevailing at the western side of the HS events, large-scale descent associated with high-pressure systems tend to suppress convection initiation (Piper and Kunz, 2017). This relation also explains why the dynamical and thermodynamical conditions in terms of DLS and SLI prevailing during HS events for the different classes are consistent among themselves.

\section{Conclusions}

In our study, we have reconstructed a large number of past severe convective storms and investigated prevailing environmental conditions over a 10-year period in central Europe. The combination of SCS tracks derived from 2D radar data with hail reports from the ESWD gave additional information on the hailstone size of a storm but also ensured that the resulting subsample consisted of hailstorms solely. The resulting HS subsample allowed us to investigate prevailing environmental conditions from reanalysis as a function of hail size and track length. In addition, we have investigated how and through which mechanisms synoptic cold fronts modify the characteristics and the frequency of SCS and HS events. Our study is the first of its kind that relies on both hail size and track length, a combination essential for the damage potential of severe hailstorms.

The main conclusions from our research are the following:

- Approximately one quarter of all SCSs across the investigation area are connected to a front, being usually prefrontal events. Over complex terrain, such as in southern Germany, the share of frontal SCSs is low (partly below $10 \%$ ), while over flat terrain a front is more often required (up to $50 \%$ of all events) to trigger convection.

- Frontal HS events on average produce larger hailstones and have longer tracks. These events preferably develop in a high-shear environment related to the cold front.

- Dynamical proxies such as DLS or SRH become important when separating between hailstorms of different 
intensity classes with respect to hail diameter and length (or likewise duration). Thermodynamic proxies such as SLI or lapse rate show only small differences around the event's centers between the different classes.

- SRH $(0-3 \mathrm{~km})$ as a dynamical proxy performs better compared to DLS when separating HS events according to hail size and track length.

- The larger the hail size is, the larger the deviation between track direction and direction of the mean wind at $500 \mathrm{hPa}$ is. Most of the large hail events $(D \geq 5 \mathrm{~cm})$ propagate to the right of the mean wind, suggesting an increased probability of right-moving supercells in that subsample of HS events.

A potential weakness of our study is that it relies on eyewitness reports (ESWD), which are biased towards more densely populated regions and towards daytime (Groenemeijer et al., 2017). This constraint reduces not only the size of the HS sample but also creates a spatial bias as can be seen in the substantially lower number of HS events in France than in Germany. Furthermore, the estimation of the largest diameter for hailstones that may substantially deviate from a sphere creates additional uncertainty.

Despite the different sources of uncertainty and the limited representativity of the reports for several regions, the comparatively large sample including approximately 1000 events enables reliable statistical analyses when aggregated over the whole investigation area. Furthermore, ESWD reports are the only dataset that gives additional information about hail diameter. Insurance loss data used in several hail-related studies (e.g., Vinet, 2001; Schuster et al., 2006; Kunz, 2007) or data from hailpad networks (e.g., Dessens and Fraile, 1994; Sánchez et al., 2017) cannot be applied because of the large spread inherent in the damage-to-diameter relation or the limited regions gauged. In the future, ground-truth observations collected through crowdsourcing via specific platforms such as the European Weather Observer app (EWOBS; Groenemeijer et al., 2017) or the MeteoSwiss app (Trefalt et al., 2018; Barras et al., 2019) might overcome the underreporting of hail events.

In our study, we have taken the HS events as the basis of the analysis and then examined prevailing environmental conditions. From a forecasting perspective, however, the reverse question is actually of great relevance: what is the probability of a severe footprint (length and hail diameter) under the current (or predicted) environmental conditions. This question, however, could not be evaluated quantitatively or probabilistically, as the hail reports archived by the ESWD are incomplete, especially over France. One possibility would be to consider only the expected lifetime (or length) of a storm cell in the prediction scheme and to ignore the hail diameter - even if this quantity is most important for the damage.
Nevertheless, the main findings and conclusions of our study can be considered in several ways. Above all, the results can (and should) be considered in the forecasting of SCSs for lead times between 1 and $12 \mathrm{~h}$. This time range is of considerable importance for many users as well as for issuing warnings of SCSs associated with high-impact weather phenomena such as hail, heavy rainfall, or severe wind gusts. In the hierarchy of prediction models, this time range is covered by nowcasting tools and very short-range forecasts (Nisi et al., 2014; James et al., 2018). Hence, convective indices, particularly SRH or DLS, might be employed in both systems. Our results can help to distinguish between less severe and more severe convection. When focusing on the most severe storms, the magnitude and temporal evolution of SRH and DLS and whether a front is nearby should be considered. Finally, because there is evidence of an increase in the number of extremely strong weather fronts during the summer over Europe (Schemm et al., 2017), our findings have implications for explaining trends and the regional-scale variability of front-related SCSs and HSs.

Data availability. 2D radar data for Germany can be downloaded via the DWD FTP server. Tracks of SCSs were calculated from DWD radar data. The track data are not freely available but may be provided upon request. The ESWD reports are available via https://www.eswd.eu/ (last access: 1 August 2018) (ESWD, 2018). ERA-Interim data can be downloaded from the ECMWF server; coastDat-3 reanalysis data can be requested from the HelmholtzZentrum Geesthacht (HZG). Front analyses can be provided upon request.

Author contributions. MK designed the research and wrote most parts of the paper. JW conducted the analyses of the environmental conditions and wrote the corresponding sections. EF performed the SCS or hail track analyses, while SB combined the tracks with ESWD data and frontal detections. SS provided the data of synoptic fronts and wrote the corresponding section. SM and SS edited the paper and provided substantial comments and constructive suggestions for scientific clarification and further improvements.

Competing interests. The authors declare that they have no conflict of interest.

Acknowledgements. The authors thank the German Weather Service (DWD) and Météo France for providing radar data, the ESSL for making available archived observations, Siemens AG (Stephan Thern) for providing lightning data, and HZG (Beate Geyer) for providing coastDat-3 hindcasts. ERAInterim data were downloaded from the ECMWF web server. Data are stored at the Research Data Archive at the Karlsruhe Institute of Technology (KIT) and are available upon request to Michael Kunz. The authors also gratefully acknowledge the two anonymous reviewers for their helpful comments and suggestions. 
Financial support. The article processing charges for this open-access publication were covered by a Research Centre of the Helmholtz Association.

Review statement. This paper was edited by Vassiliki Kotroni and reviewed by two anonymous referees.

\section{References}

Aran, M., Pena, J., and Torà, M.: Atmospheric circulation patterns associated with hail events in Lleida (Catalonia), Atmos. Res., 100, 428-438, 2011.

Barras, H., Hering, A., Martynov, A., Noti, P.-A., Germann, U., and Martius, O.: Experiences with $>50000$ crowd-sourced hail reports in Switzerland, B. Am. Meteorol. Soc., 100, 1429-1440, 2019.

Barthlott, C., Burton, R., Kirshbaum, D., Hanley, K., Richard, E., Chaboureau, J.-P., Trentmann, J., Kern, B., Bauer, H.-S., Schwitall, T., Keil, C., Seity, Y., Gadian, A., Blyth, A., Mobbs, S., Flamant, C., and Handwerker, J.: Initiation of deep convection at marginal instability in an ensemble of mesoscale models: A case study from COPS, Q. J. Roy. Meteorol. Soc., 137, 118136, 2011.

Bedka, K. M.: Overshooting cloud top detections using MSG SEVIRI Infrared brightness temperatures and their relationship to severe weather over Europe, Atmos. Res., 99, 175-189, 2011.

Berthet, C., Dessens, J., and Sanchez, J. L.: Regional and yearly variations of hail frequency and intensity in France, Atmos. Res., 100, 391-400, 2011.

Bunkers, M. J., Klimowski, B. A., Zeitler, J. W., Thompson, R. L., and Weisman, M. L.: Predicting supercell motion using a new hodograph technique, Weather Forecast., 15, 61-79, 2000.

Changnon, S. A.: The scales of hail, J. Appl. Meteorol., 16, 626648, 1977.

Chronis, T., Carey, L. D., Schultz, C. J., Schultz, E. V., Calhoun, K. M., and Goodman, S. J.: Exploring lightning jump characteristics, Weather Forecast., 30, 23-37, 2015.

Dee, D. P., Uppala, S., Simmons, A., Berrisford, P., Poli, P., Kobayashi, S., Andrae, U., Balmaseda, M., Balsamo, G., Bauer, P., Bechtold, P., Beljaars, A. C. M., van de Berg, L., Bidlot, J., Bormann, N., Delsol, C., Dragani, R., Fuentes, M., Geer, A. J., Haimberger, L., Healy, S. B., Hersbach, H., Hólm, E. V., Isaksen, L., Kållberg, P., Köhler, M., Matricardi, M., McNally, A. P., Monge-Sanz, B. M., Morcrette, J.-J., Park, B.-K., Peubey, C., de Rosnay, P., Tavolato, C., Thépaut, J.-N., and Vitart, F.: The ERA-Interim reanalysis: Configuration and performance of the data assimilation system, Q. J. Roy. Meteorol. Soc., 137, 553597, 2011

Dennis, E. J. and Kumjian, M. R.: The impact of vertical wind shear on hail growth in simulated supercells, J. Atmos. Sci., 74, 641663, 2017.

Dessens, J. and Fraile, R.: Hailstone size distributions in southwestern France, Atmos. Res., 33, 57-73, 1994.

Dickinson, M. J. and Knight, D. J.: Frontal interaction with mesoscale topography, J. Atmos. Sci., 56, 3544-3559, 1999.

Dotzek, N., Groenemeijer, P., Feuerstein, B., and Holzer, A. M.: Overview of ESSL's severe convective storms research using the
European Severe Weather Database ESWD, Atmos. Res., 93, 575-586, 2009.

Emanuel, K. A.: Frontal circulations in the presence of small moist symmetric stability, J. Atmos. Sci., 42, 1062-1071, 1985.

ESWD: European Severe Weather Database, available at: https:// www.eswd.eu/, last access: 1 August 2018.

Fluck, E.: Hail potential over Western Europe, PhD thesis, KIT Karlsruhe Institute of Technology, Karlsruhe, Germany, 2017.

Foote, G. B.: A study of hail growth utilizing observed storm conditions, J. Clim. Appl. Meteorol., 23, 84-101, 1984.

Galway, J. G.: The lifted index as a predictor of latent instability, B. Am. Meteorol. Soc., 37, 528-529, 1956.

García-Ortega, E., López, L., and Sánchez, J.: Atmospheric patterns associated with hailstorm days in the Ebro Valley, Spain, Atmos. Res., 100, 401-427, 2011.

Giaiotti, D., Nordio, S., and Stel, F.: The climatology of hail in the plain of Friuli Venezia Giulia, Atmos. Res., 67-68, 247-259, 2003.

Graf, M. A., Sprenger, M., and Moore, R. W.: Central European tornado environments as viewed from a potential vorticity and Lagrangian perspective, Atmos. Res., 101, 31-45, 2011.

Groenemeijer, P., Púčik, T., Holzer, A. M., Antonescu, B., RiemannCampe, K., Schultz, D. M., Kühne, T., Feuerstein, B., Brooks, H. E., Doswell III, C. A., Koppert, H.-J., and Sausen, R.: Severe convective storms in Europe: Ten years of research and education at the European Severe Storms Laboratory, B. Am. Meteorol. Soc., 98, 2641-2651, 2017.

Groenemeijer, P. H. and van Delden, A.: Sounding-derived parameters associated with large hail and tornadoes in the Netherlands, Atmos. Res., 83, 473-487, 2007.

Handwerker, J.: Cell tracking with TRACE3D - a new algorithm, Atmos. Res., 61, 15-34, 2002.

Heinselman, P. L. and Ryzhkov, A. V.: Validation of polarimetric hail detection, Weather Forecast., 21, 839-850, 2006.

Hermida, L., López, L., Merino, A., Berthet, C., García-Ortega, E., Sánchez, J. L., and Dessens, J.: Hailfall in southwest France: Relationship with precipitation, trends and wavelet analysis, Atmos. Res., 156, 174-188, 2015.

Hewson, T. D.: Objective fronts, Meteorol. Appl., 5, 37-65, 1998.

Hohl, R., Schiesser, H. H., and Knepper, I.: The use of weather radars to estimate hail damage to automobiles: An exploratory study in Switzerland, Atmos. Res., 61, 215-238, 2002.

Holleman, I., Wessels, H. R. A., Onvlee, J. R. A., and Barlag, S. J. M.: Development of a hail-detection-product, Phys. Chem. Earth Pt. B, 25, 1293-1297, 2000.

James, P. M., Reichert, B. K., and Heizenreder, D.: NowCastMIX: Automatic integrated warnings for severe convection on nowcasting time scales at the German Weather Service, Weather Forecast., 33, 1413-1433, 2018.

Junghänel, T., Brendel, C., Winterrath, T., and Walter, A.: Towards a radar-and observation-based hail climatology for Germany, Meteorol. Z., 25, 435-445, 2016.

Kapsch, M.-L., Kunz, M., Vitolo, R., and Economou, T.: Long-term trends of hail-related weather types in an ensemble of regional climate models using a Bayesian approach, J. Geophys. Res., 117, D15107, https://doi.org/10.1029/2011JD017185, 2012.

Klemp, J. B.: Dynamics of tornadic thunderstorms, Annu. Rev. Fluid Mech., 19, 369-402, 1987. 
Kunz, M.: The skill of convective parameters and indices to predict isolated and severe thunderstorms, Nat. Hazards Earth Syst. Sci., 7, 327-342, https://doi.org/10.5194/nhess-7-327-2007, 2007.

Kunz, M. and Kugel, P.: Detection of hail signatures from 3D CBand radar reflectivity, Atmos. Res., 153, 565-577, 2015.

Kunz, M. and Puskeiler, M.: High-resolution assessment of the hail hazard over complex terrain from radar and insurance data, Meteorol. Z., 19, 427-439, 2010.

Kunz, M., Blahak, U., Fluck, E., Punge, H., Schmidberger, M., Handwerker, J., Mohr, M., Mühr, B., and Bedka, K.: The severe hailstorm in SW Germany on 28 July 2013: Characteristics, impacts, and meteorological conditions, Q. J. Roy. Meteorol. Soc., 144, 231-250, 2018.

Löffler-Mang, M., Kunz, M., and Kossmann, M.: A nocturnal cold front over complex terrain and its influence on the ozone concentrations at the ground, Meteorol. Z., 5, 308-317, 1996.

Lukach, M., Foresti, L., Giot, O., and Delobbe, L.: Estimating the occurrence and severity of hail based on 10 years of observations from weather radar in Belgium, Meteorol. Appl., 24, 250-259, 2017

Madonna, E., Ginsbourger, D., and Martius, O.: A Poisson regression approach to model monthly hail occurrence in Northern Switzerland using large-scale environmental variables, Atmos. Res., 203, 261-274, 2018.

Manzato, A.: A climatology of instability indices derived from Friuli Venezia Giulia soundings, using three different methods, Atmos. Res., 67, 417-454, 2003.

Manzato, A.: The use of sounding-derived indices for a neural network short-term thunderstorm forecast, Weather Forecast., 20, 896-917, 2005.

Markowski, P. and Richardson, Y.: Mesoscale meteorology in midlatitudes, John Wiley \& Sons, Chichester, UK, 407 pp., 2010.

Mason, B. J.: The physics of clouds, Oxford University Press, Clarendon Press, Oxford, New York, USA, 671 pp., 1971.

Mathias, L., Ermert, V., Kelemen, F. D., Ludwig, P., and Pinto, J. G.: Synoptic analysis and hindcast of an intense bow echo in Western Europe: The 9 June 2014 storm, Weather Forecast., 32, 1121-1141, 2017.

Merino, A., Wu, X., Gascón, E., Berthet, C., García-Ortega, E., and Dessens, J.: Hailstorms in southwestern France: Incidence and atmospheric characterization, Atmos. Res., 140, 61-75, 2014.

Mohr, S. and Kunz, M.: Recent trends and variabilities of convective parameters relevant for hail events in Germany and Europe, Atmos. Res., 123, 211-228, 2013.

Mohr, S., Wandel, J., Lenggenhager, S., and Martius, O.: Relationship between atmospheric blocking and warm-season thunderstorms over western and central Europe, Q. J. Roy. Meteorol. Soc., 145, 3040-3056, 2019.

Mohr, S., Wilhelm, J., Wandel, J., Kunz, M., Portmann, R., Punge, H. J., Schmidberger, M., and Grams, C. M.: The role of largescale dynamics in an exceptional sequence of severe thunderstorms in Europe May/June 2018, Weather Clim. Dynam. Discuss., https://doi.org/10.5194/wcd-2020-1, in review, 2020.

Morris, R. M.: The Spanish plume-testing the forecaster's nerve, Meteorol. Mag., 115, 349-357, 1986.

Mroz, K., Battaglia, A., Lang, T. J., Cecil, D. J., Tanelli, S., and Tridon, F.: Hail-detection algorithm for the GPM core observatory satellite sensors, J. Appl. Meteorol. Clim., 56, 1939-1957, 2017.
MunichRe: NatCatSERVICE, available at: https://natcatservice. munichre.com/, last access: 4 May 2020.

Ni, X., Liu, C., Cecil, D. J., and Zhang, Q.: On the detection of hail using satellite passive microwave radiometers and precipitation radar, J. Appl. Meteorol. Clim., 56, 2693-2709, 2017.

Nisi, L., Ambrosetti, P., and Clementi, L.: Nowcasting severe convection in the Alpine region: The COALITION approach, Q. J. Roy. Meteorol. Soc., 140, 1684-1699, 2014.

Nisi, L., Martius, O., Hering, A., Kunz, M., and Germann, U.: Spatial and temporal distribution of hailstorms in the Alpine region: A long-term, high resolution, radar-based analysis, Q. J. Roy. Meteorol. Soc., 142, 1590-1604, 2016.

Nisi, L., Hering, A., Germann, U., and Martius, O.: A 15-year hail streak climatology for the Alpine region, Q. J. Roy. Meteorol. Soc., 144, 1429-1449, 2018.

Piper, D. and Kunz, M.: Spatiotemporal variability of lightning activity in Europe and the relation to the North Atlantic Oscillation teleconnection pattern, Nat. Hazards Earth Syst. Sci., 17, 13191336, https://doi.org/10.5194/nhess-17-1319-2017, 2017.

Piper, D., Kunz, M., Allen, J., and Mohr, S.: Investigation of the temporal variability of thunderstorms in central and western Europe and the relation to large-scale flow and teleconnection patterns, Q. J. Roy. Meteorol. Soc., 145, 3644-3666, 2019.

Púčik, T., Groenemeijer, P., Rva, D., and Kolár̆, M.: Proximity soundings of severe and non-severe thunderstorms in Central Europe, Mon. Weather Rev., 143, 4805-4821, 2015.

Púčik, T., Castellano, C., Groenemeijer, P., Kühne, T., Rädler, A. T., Antonescu, B., and Faust, E.: Large hail incidence and its economic and societal impacts across Europe, Mon. Weather Rev., 147, 3901-3916, 2019.

Punge, H. and Kunz, M.: Hail observations and hailstorm characteristics in Europe: A review, Atmos. Res., 176-177, 159-184, 2016.

Punge, H., Bedka, K., Kunz, M., and Reinbold, A.: Hail frequency estimation across Europe based on a combination of overshooting top detections and the ERA-INTERIM reanalysis, Atmos. Res., 198, 34-43, 2017.

Puskeiler, M., Kunz, M., and Schmidberger, M.: Hail statistics for Germany derived from single-polarization radar data, Atmos. Res., 178-179, 459-470, 2016.

Renard, R. J. and Clarke, L. C.: Experiments in numerical objective frontal analysis, Mon. Weather Rev., 93, 547-556, 1965.

Rockel, B., Will, A., and Hense, A.: The Regional Climate Model COSMO-CLM (CCLM), Meteorol. Z., 17, 347-348, 2008.

Ryzhkov, A. V. and Zrnic, D. S.: Polarimetric Characteristics of Deep Convective Storms, in: Radar polarimetry for weather observations, eBook, Springer Atm. Sci., Springer, Cham, 2019.

Ryzhkov, A. V., Kumjian, M. R., Ganson, S. M., and Khain, A. P.: Polarimetric radar characteristics of melting hail. Part I: Theoretical simulations using spectral microphysical modeling, J. Appl. Meteorol. Clim., 52, 2849-2870, 2013.

Sánchez, J., Merino, A., Melcón, P., García-Ortega, E., FernándezGonzález, S., Berthet, C., and Dessens, J.: Are meteorological conditions favoring hail precipitation change in Southern Europe? Analysis of the period 1948-2015, Atmos. Res., 198, 1-10, 2017.

Sánchez, J. L., Marcos, J. L., Dessens, J., López, L., Bustos, C., and García-Ortega, E.: Assessing sounding-derived parameters 
as storm predictors in different latitudes, Atmos. Res., 93, 446456, 2009.

Schemm, S., Rudeva, I., and Simmonds, I.: Extratropical fronts in the lower troposphere-global perspectives obtained from two automated methods, Q. J. Roy. Meteorol. Soc., 141, 1686-1698, 2015

Schemm, S., Nisi, L., Martinov, A., Leuenberger, D., and Martius, O.: On the link between cold fronts and hail in Switzerland, Atmos. Sci. Lett., 17, 315-325, 2016.

Schemm, S., Sprenger, M., Martius, O., Wernli, H., and Zimmer, M.: Increase in the number of extremely strong fronts over Europe? A study based on ERA-Interim reanalysis (1979-2014), Geophys. Res. Lett., 44, 553-561, 2017.

Schuster, S. S., Blong, R. J., and McAneney, K. J.: Relationship between radar-derived hail kinetic energy and damage to insured buildings for severe hailstorms in Eastern Australia, Atmos. Res., 81, 215-235, 2006.

Smart, J. R. and Alberty, R. L.: The NEXRAD hail algorithm applied to Colorado thunderstorms, in: Preprints, 14th Conf. on Severe Local Storms, Indianapolis, IN, USA, 244-247, 1985.

SwissRe: Sigma - Natural catastrophes and man-made disasters in 2014: convective and winter storms generate most losses, Tech. rep., Swiss Re Economic Research and Consulting, Switzerland, 2015.

Thompson, R. L., Mead, C. M., and Edwards, R.: Effective stormrelative helicity and bulk shear in supercell thunderstorm environments, Weather Forecast., 22, 102-115, 2007.

Trapp, R. J.: Mesoscale-convective processes in the atmosphere, Cambridge University Press, Cambridge, New York, USA, 2013.
Trefalt, S., Martynov, A., Barras, H., Besic, N., Hering, A. M., Lenggenhager, S., Noti, P., Röthlisberger, M., Schemm, S., Germann, U., and Martius, O.: A severe hail storm in complex topography in Switzerland - Observations and processes, Atmos. Res., 209, 76-94, 2018.

Vinet, F.: Climatology of hail in France, Atmos. Res., 56, 309-323, 2001.

Waldvogel, A., Federer, B., and Grimm, P.: Criteria for the detection of hail cells, J. Appl. Meteorol., 18, 1521-1525, 1979.

Wandel, J.: Analyse der Umgebungsbedingungen während Hagelereignissen, MS thesis, Institute of Meteorology and Climate Research, KIT - Karlsruhe Institute of Technology KIT, Karlsruhe, Germany, 101 pp., 2017.

Wapler, K.: High-resolution climatology of lightning characteristics within Central Europe, Meteorol. Atmos. Phys., 122, 175-184, 2013.

Wapler, K.: The life-cycle of hailstorms: Lightning, radar reflectivity and rotation characteristics, Atmos. Res., 193, 60-72, 2017.

Wapler, K. and James, P.: Thunderstorm occurrence and characteristics in Central Europe under different synoptic conditions, Atmos. Res., 158, 231-244, 2015.

Weckwerth, T. and Parsons, D. B.: A review of convection initiation and motivation for IHOP_2002, Mon. Weather Rev., 134, 5-22, 2005.

Weisman, M. L. and Klemp, J. B.: The dependence of numerically simulated convective storms on vertical wind shear and buoyancy, Mon. Weather Rev., 110, 504-520, 1982.

Witt, A., Eilts, M. D., Stumpf, G. J., Johnson, J. T., Mitchell, E. D. W., and Thomas, K. W.: An enhanced hail detection algorithm for the WSR-88D, Weather Forecast., 13, 286-303, 1998. 